\title{
LA ESTRUCTURA RESISTENTE DE LOS EDIFICIOS ALTOS*
}

\author{
(THE RESISTANT STRUCTURE IN HIGH BUILDINGS) \\ Javier Manterola Armisen, Dr. Ingeniero de Caminos.
}

\section{RESUMEN}

Si consideramos únicamente el problema resistente, un edificio alto podría considerarse como una gran ménsula vertical. Las exigencias resistentes de esta gran ménsula son más apremiantes conforme el edificio crece en altura y su acoplamiento a las necesidades funcionales del edificio mas dificil.

En este artículo se pasa revista a las diversas tipologías resistentes, desde la estructura aporticada normal de los edificios de altura moderada hasta el "tubo en el tubo" y estructuras laminares totales correspondientes a los más altos edificios construidos y por construir.

Se hace un análisis de la forma de resistir de cada una de las tipologias ilustrándolas con ejemplos de edificios construidos.

\section{SUMMARY}

If we only think about the resistance problem, a building could be considered as a great vertical console. The resistant exigencies of this huge console are as pressing as the building grows up and its fitting to the functional needs are more difficult

This study reviews the different resistant typologies, from the normal porch structure of medium size buildings to the "tube into the tube" and total laminar structures corresponding to the higher buildings which are already built, or are to be built.

It also makes an analysis on the manner in which each typology resist, and shows examples of constructed buildings.
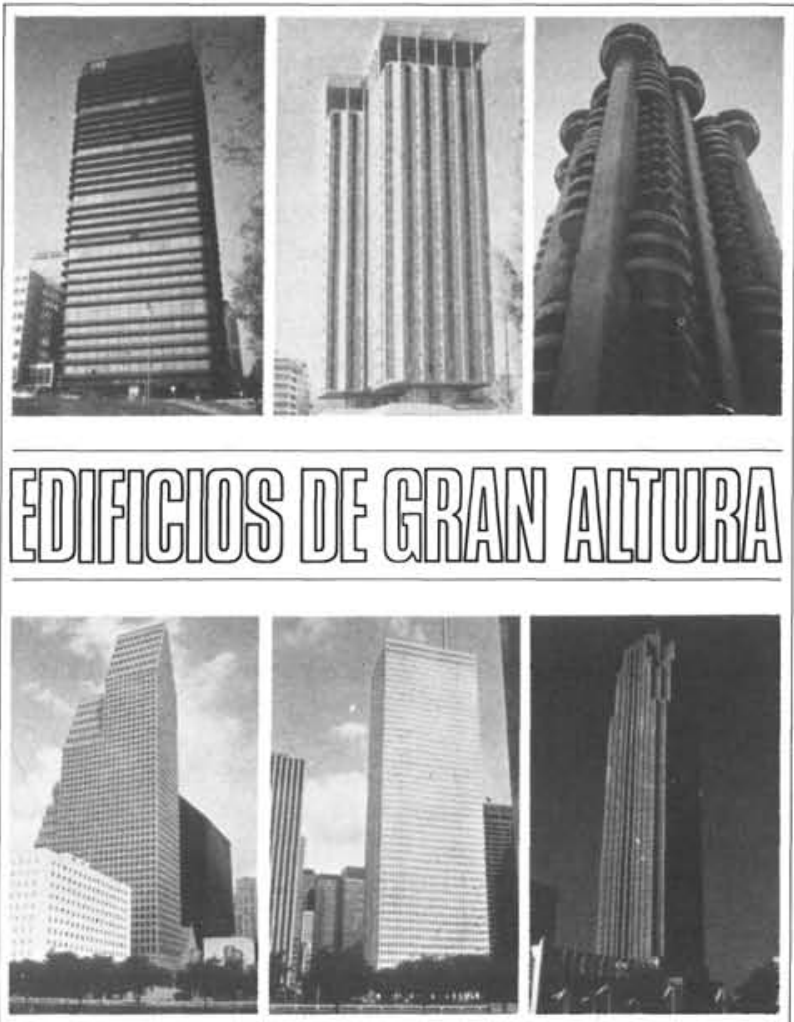

\section{INTRODUCCION}

Un edificio, cualquier edificio, está sometido a una serie de acciones provenientes del medio que la estructura debe resistir. Tenemos las acciones gravitatorias, el viento, el sismo, las variaciones de temperatura, la fluencia, la retracción, etc. Unas son acciones directas, otras deformaciones impuestas ante las que la estructura debe responder con adecuado coeficiente de seguridad, sin perturbar al usuario o a las demás estructuras constitutivas del edificio con deformaciones o movimientos excesivos.

Desde la aparición de los materiales modernos, acero y hormigón, la estructura resistente se ha adecuado a las condiciones funcionales del edificio imponiendo unos condicionantès mínimos. Se ha convertido en una serie de pilares verticales que sostienen unos forjados más o menos complejos. Las acciones gravitarorias son las únicas que determinan la forma y cuantía de la estructura. Las demás acciones son resistidas sin que su influencia interfiera apenas en el diseño.

Como las luces requeridas para cumplir las condiciones funcionales son pequeñas, la estructura resistente de los edificios normales ha dejado de te-

* Conferencia dada en el Instituto Eduardo Torroja, en el Curso CEMCO-85. 
ner importancia. Las posibilidades de la tecnología actual son tan superabundantes que cualquier exigencia impuesta por las condiciones funcionales puede resolver la estructura sin que las desviaciones de su coste influyan demasiado en el coste total. Desde este punto de vista la estructura resistente ha perdido su valor conformador del edificio. Queda reducida a una estructura más de las que lo constituyen.

Sin embargo, cuando el edificio es alto, las acciones producen esfuerzos muy importantes en la estructura resistente, la cual debe adoptar configuraciones determinadas para controlar su precio y no interferir demasiado con las otras estructuras del edificio. El problema resistente toma una gran importancia y la estructura que lo resuelve vuelve a tener valor conformador.

\section{ACCIONES}

Las acciones que solicitan a un edificio alto son las mismas que a un edificio normal, pero su efecto es muy diferente.

Las acciones gravitarorias, tanto de peso propio como de servicio, producen un efecto creciente con la altura por su acumulación a lo largo del número de plantas, lo que determina un incremento importante en el tamaño de los soportes. La actuación sobre ellos ha conducido en muchas estructuras de hormigón a utilizar hormigones ligeros en forjados, con densidades que oscilan entre 1.700 y $1.900 \mathrm{~kg} /$ $\mathrm{m}^{3}$, lo que supone un alivio apreciable en el peso del edificio, además de usar hormigones de alta resistencia, en pilares, en las plantas inferiores.

Las acciones horizontales, constituidas principalmente por la presión del viento y las fuerzas de inercia producidas en los movimientos sísmicos, son las acciones significativas de cara a determinar la estructura resistente en los edificios altos. Ante ellas el edificio es una ménsula.

Las acciones de viento, consideradas generalmente en su dimensión estática, dependen de la velocidad del viento para un determinado período de retorno - de la altura, superficie y forma del edificio- del lugar donde está inscrito. La cuantía de la solicitación debe ser obtenida en modelos sometidos a ensayos en túnel de viento. El valor dado por los distintos códigos nacionales suele ser una aproximación más o menos grosera, válida únicamente cuando la altura del edificio es moderada.

Las acciones sísmicas son más complejas dado que su valor no sólo depende de la aceleración del suelo, para un determinado período de retorno, sino también de las características de la estructura resistente, de su masa, rigidez y amortiguamiento, que determinan los modos naturales de vibración y los períodos. Generalmente las estructuras flexibles, de grandes períodos de vibración, desarrollan fuerzas sísmicas más pequeñas, pero a su vez son más deformables, lo que puede producir daños en los elementos no estructurales del edificio y falta de confort en los usuarios. La ductilidad de los elementos estructurales toman significativa importancia ante estas acciones.

Las variaciones de temperatura en general y las deformaciones impuestas por la fluencia y la retracción en las estructuras de hormigón, que en edificios normales no conducen sino a determinar la posición de las juntas de dilatación, en los edificios altos pueden producir esfuerzos muy significativos en los forjados por acumulación de alargamientos o acortamientos en las últimas plantas.

Especial importancia toma el control de las temperaturas en los pilares expuestos al medio ambiente, cuando los interiores pueden estar en un ambiente controlado.

\section{MOVIMIENTOS}

La altura del edificio no sólo determina una cuantía muy importante de los esfuerzos debido a las acciones horizontales, sino también unos movimientos grandes. La estructura resistente deberá controlar ambos, esfuerzos y corrimientos, y muchas veces son los segundos los que la determinan.

El movimiento es necesario controlarlo por dos razones: la conservación de los elementos no estructurales del edificio, como son los cerramientos interiores y exteriores y las comunicaciones verticales; en segundo lugar, el confort de sus usuarios.

No existe aún una normativa clara de cuál debe ser el desplazamiento máximo que puede admitirse entre techo y suelo de cualquier planta o de los desplazamientos máximos en la parte superior. Las experiencias americanas recomiendan no pasar de desplazamientos de $1 / 400$ a 1/600 de la altura de la planta o edificio. En el caso de edificios con cerramientos importantes se pueden reducir los desplazamientos a 1/300 de la altura, siempre que no se cuenten éstos en la respuesta resistente.

En cuanto al criterio a seguir para determinar cuál es el confort de las personas ante las oscilaciones producidas en el edificio por el viento y el sismo, resulta discutible ya que las personas responden de diferente manera ante este hecho. La aproximación al problema establece una gradación en función de la aceleración en cuatro zonas: no perceptible, escasamente perceptible, perceptible y molesta. Según Khan y Parmelee:

No perceptible...... aceleración menor $0,004 \mathrm{~g}$.

Raramente perceptible. aceleración entre $0,004 \mathrm{~g}$ y $0,0075 \mathrm{~g}$. 
Intormes de a Construcción Vol $37, n^{\circ} 371$, unio, 1985

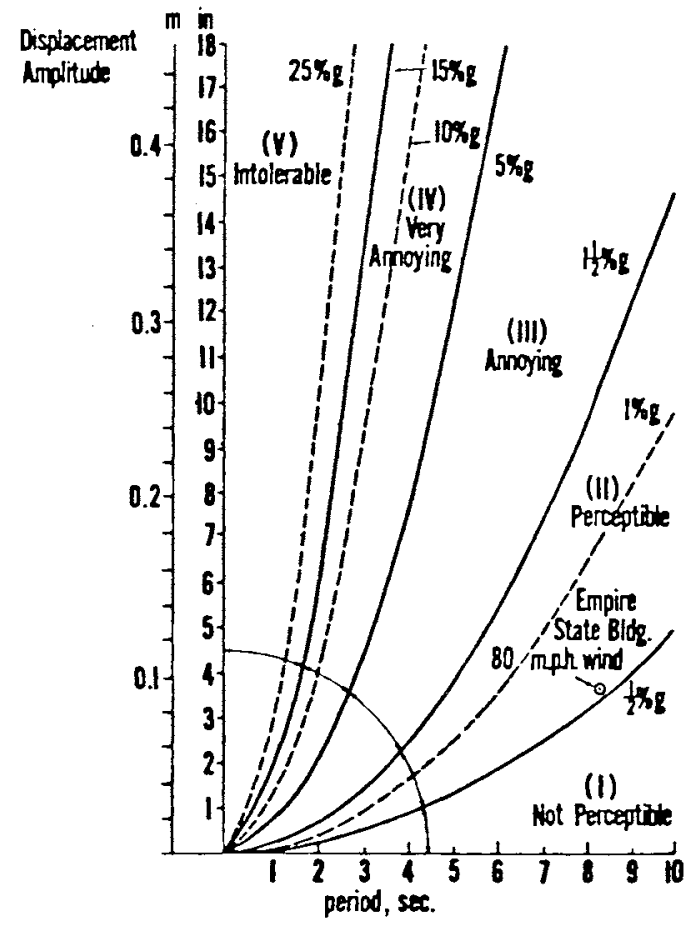

FIGURA 1

Perceptible......... aceleración entre $0,0075 \mathrm{~g}$ y $0,02 \mathrm{~g}$.

Molesta........... aceleración mayor 0,02 g.

$$
\mathrm{g}=9,81 \mathrm{~m} / \mathrm{seg}^{2}
$$

Chang ha representado los límites del confort en función de la relación entre el período y la amplitud de la vibración (Fig. 1).

\section{LA ESTRUCTURA RESISTENTE}

La estructura resistente de un edificio alto es una gran ménsula vertical sometida a cargas horizontales y verticales. El problema resistente de una ménsula bien conformada es muy simple. Es un elemento solicitado principalmente a cortante y a flexión, y su respuesta está perfectamente resuelta por la tecnología actual para las grandes ménsulas que se le han presentado en puentes y torres de comunicaciones.

En un edificio, las condiciones funcionales y de uso interfieren definitivamente en la conformación lógica de la ménsula, convirtiéndola en una estructura espacial muy compleja, hueca y con dificultades grandes para disponer en su interior las almas necesarias para una adecuada resistencia al cortante $y$ un desarrollo correcto del mecanismo de flexión entre las caras límites del edificio.

Definir un edificio alto como una ménsula mal conformada por las exigencias de su uso es un dispara- te. Sin embargo, aquí nos interesa, pues destaca, el problema que va a configurar el camino a seguir en el diseño de su estructura resistente. Esta ménsula hueca y definitivamente perforada va a ser muy deformable a cortante, lo que reduce enormemente la capacidad de resistencia a flexión que el volumen del edificio podría proporcionar. Conforme el edificio sea más alto, la lucha contra la deformación a cortante será más exigente y la estructura irá tomando morfologías más condicionadas.

Veamos cuáles son los tipos de estructuras resistentes con que contamos en la actualidad, empezando por las estructuras más simples para los edificios menos altos, hasta las más condicionadas por la altura.

\subsection{Estructura pórtico}

Esta estructura es la normalmente utilizada por los edificios normales. Está constituida por pilares verticales empotrados en las losas que constituyen el forjado del edificio. Su configuración viene determinada principalmente por las cargas verticales, e interfiere muy escasamente con las necesidades funcionales del edificio.

Veamos cuál es su respuesta bajo las acciones horizontales. En un planteamiento simplificado se pueden distinguir dos mecanismos de resistencia (Fig. 2):

1. Suponiendo que los puntos de inflexión de la deformada se producen en el centro de los pilares y el cortante total de las fuerzas exteriores en ese punto es $\mathrm{V}$, el equilibrio de las células elementales (Fig. 2.b) nos da que el ángulo $\vartheta$ de giro del nudo es:

$$
\vartheta=\frac{V \cdot h \cdot \ell}{12 \cdot E \cdot I_{v}}
$$

donde $\frac{E \cdot I_{v}}{1}$ es la rigidez de las vigas horizontales.

El desplazamiento $\delta$ será:

$$
\delta=\frac{V \cdot h^{2}}{24 \cdot E}\left(\frac{\ell}{I_{v}}+\frac{h}{l_{p}}\right)
$$

Este corrimiento equivale a una deformación por cortante si considerásemos que el cuadrado elemental formado por dos vigas y dos pilares es un elemento diferencial de una viga cuyas dimensiones coinciden con la superficie del pórtico múltiple. 


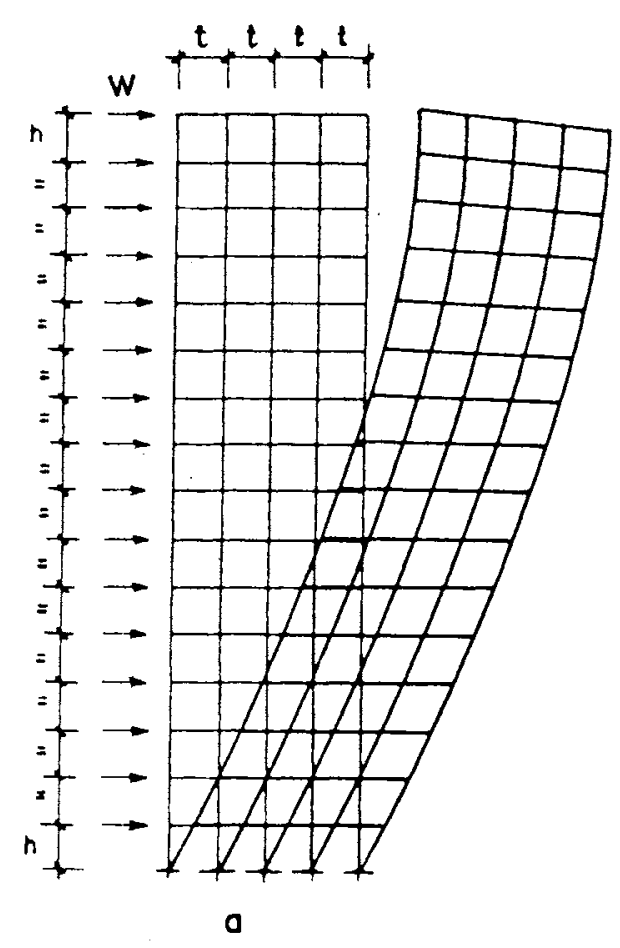

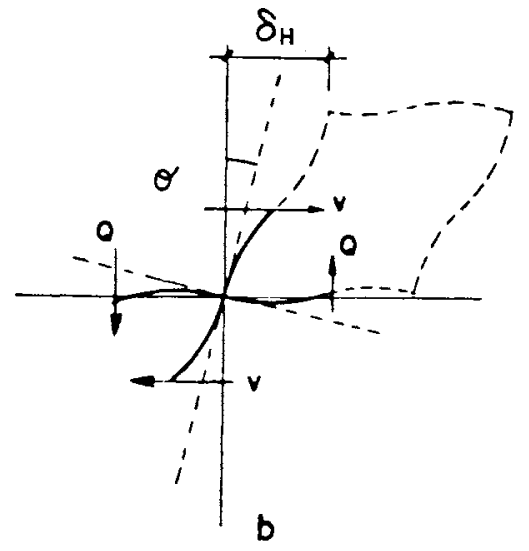
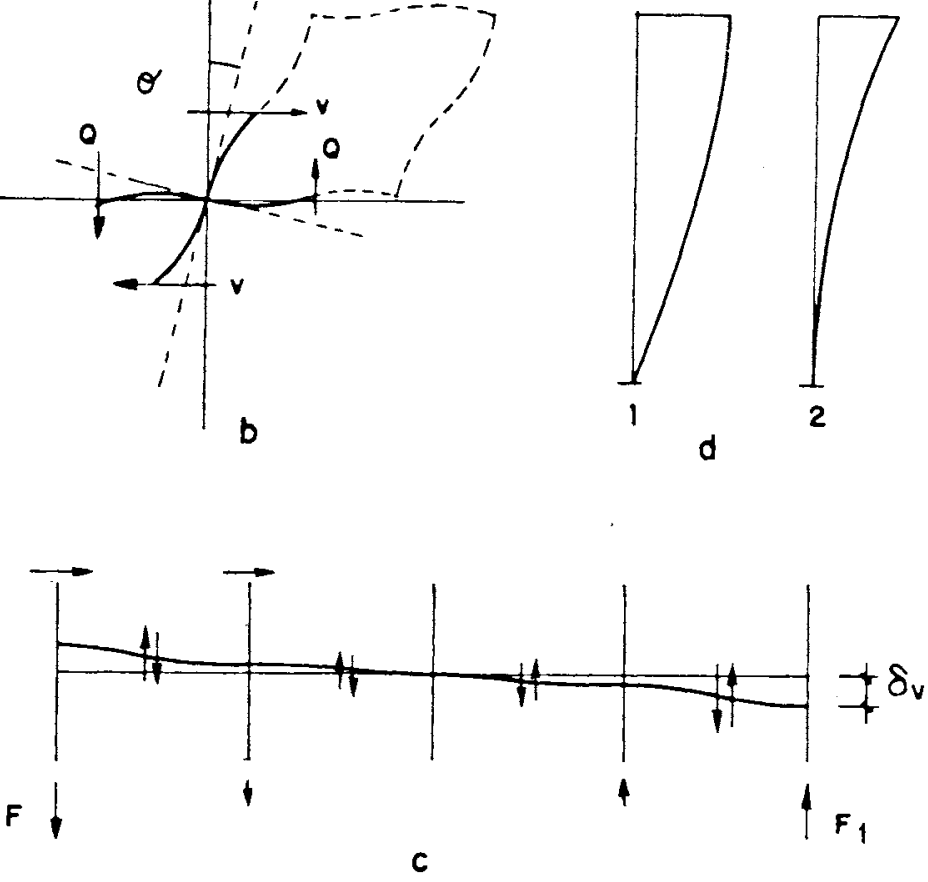

FIGURA 2
En este caso:

$$
\frac{V}{G \cdot A} \cdot \frac{h}{2}=\delta=\frac{V \cdot h^{2}}{24 \cdot E}\left(\frac{\ell}{I_{V}}+\frac{h}{I_{p}}\right)
$$

de donde se deduce que la rigidez a cortante de dicha viga es:

$$
\frac{1}{G \cdot A}=\frac{h}{12 \cdot E}\left(\frac{1}{I_{v} / \ell}+\frac{1}{I_{p} / h}\right)
$$

La ecuación diferencial que gobierna el comportamiento a cortante del pórtico será:

$$
-G \cdot A \frac{d^{2} \cdot y}{d x^{2}}=w(x)
$$

y la flecha $y$, en el caso de que $w(x)$ sea uniforme a lo largo de la altura es (Fig. 2.d, 1):

$$
y=\frac{w \cdot H^{2}}{G \cdot A}\left[\frac{x}{H}-\frac{1}{2}\left(\frac{x}{H}\right)^{2}\right]
$$

2. En el centro de cada viga aparece un esfuerzo cortante $Q$ cuyo valor es:

$$
\mathrm{Q}=\mathrm{V} \cdot \frac{\mathrm{h}}{\ell}
$$

Todos los cortantes se equilibran entre sí, salvo en los pilares extremos donde se producirá un axil $F$.

Esta carga se transmite hacia la cimentación del pórtico produciendo su correspondiente acortamiento y alargamiento en los pilares extremos, lo cual supondrá un descenso diferencial de las vigas horizontales (Fig. 2.c). Este asiento solicita a las vigas obligando a una redistribución de los cortantes $Q$ hasta encontrar su equilibrio en un conjunto de fuerzas axiles en los pilares, cuya resultante vertical es cero, pero su momento equivale a $V \cdot h$.

La deformación axil de los pilares verticales ocasiona el correspondiente desplazamiento lateral del pórtico. Esta deformación equivale a una deformación de flexión de la ménsula que representa el pórtico múltiple (Fig. 2.d, 2).

Es claro que este segundo mecanismo de comportamiento invalida las hipótesis establecidas en el primero - que los puntos de momento nulo se produzcan en el centro de las vigas y pilares-, pero como aproximación nos sirve cuando la altura del pórtico no es muy grande y las rigideces de vigas y pilares no es excesiva. 
C. K. Chan y otros, establecen un método aproximado del cálculo de pórticos múltiples en que se tiene en cuenta la deformación conjunta de flexión y cortante $\left(^{*}\right)$. Este procedimiento es adecuado cuando se quiere realizar un cálculo aproximado. Un cálculo exacto puede hacerse hoy en día con cualquier programa de barras en un ordenador de tipo medio.

En un edificio de hormigón la estructura pórtico puede estar materializada en algunos casos; en otros, las vigas no existen materialmente sino que el pilar se empotra en una losa. En este caso las condiciones de rigidez de la viga equivalente a que puede reducirse la losa es mucho más complicado. Depende de la geometría en planta, de la luz entre pilares y la separación de los pórticos virtuales que puedan destacarse. Con limitaciones puede tomarse como viga equivalente la losa cuya anchura es la mitad del intereje entre pórticos virtuales. Sin embargo, la realidad se aproxima más a tomar como anchura toda la distancia que existe entre pórticos virtuales para el centro de la luz $y$ tres o cuatro veces el espesor de la losa en las proximidades del pilar.

En edificios con estructura metálica este problema no se presenta, pues el pórtico real está materializado por vigas y pilares.

Como resumen del comportamiento resistente de una estructura aporticada ante cargas horizontales, podemos decir:

1. ${ }^{\circ}$ Se desarrolla un mecanismo de resistencia a cortante, cuya rigidez depende de las relaciones $\mathrm{I}_{\mathrm{v}} / \ell$ e $\mathrm{I}_{\mathrm{p}} / \mathrm{h}$.

$2 .^{\circ}$ Se desarrolla un mecanismo de resistencia a flexión cuya rigidez depende del área y número de los pilares y de la altura y anchura del edificio.

3. El mecanismo de resistencia a flexión es activado por el mecanismo de resistencia a cortante, de manera que si este último es muy deformable, el mecanismo de resistencia a flexión no se pone en juego.

En los edificios de altura moderada, menores de 10 ó 15 plantas, la deformabilidad a cortante es bastante grande y el mecanismo de flexión no entra apenas en la contribución a resistir las cargas horizontales. Sin embargo, como la solicitación horizontal también es pequeña, la resistencia y los corrimientos del edificio quedan controlados.

Conforme el edificio crece en altura la deformabilidad del edificio crece hasta sobrepasar los límites admisibles, y los esfuerzos en vigas y pilares aumentan extraordinariamente. El mecanismo de flexión incrementa un poco su eficacia, pero no de

manera determinante como para aliviar la gran deformabilidad a cortante de la estructura aporticada. Resulta necesario acudir a otras disposiciones estructurales más eficaces.

\subsection{Pantallas}

La primera alternativa a la estructura pórtico consiste en introducir rigidez a flexión en los elementos verticales, es decir, disponer una serie de pantallas - caracterizadas por su pequeño espesor y gran canto- que, distribuidas a lo largo y ancho del edificio, sean las encargadas de recoger las cargas horizontales y verticales para transmitirlas al suelo (Fig. 3).

Su distribución en planta debe ser tal que proporcione rigidez a flexión y torsión al edificio. La primera condición se consigue dando suficiente canto a las pantallas; la segunda, estableciendo suficiente distancia entre ellas para que ante fuerzas no centradas desarrollen el par torsor suficiente. A ser posible deben adoptar una distribución simétrica en el edificio para evitar solicitaciones torsoras complementarias.

Al forjado se le asigna el papel de transmitir la carga horizontal y vertical a las pantallas. La primera condición la cumple siempre que, en sí mismo, tenga una rigidez a flexión suficiente en su plano. En el caso de forjados de hormigón esta condición suele cumplirse automáticamente. En el caso de forjados metálicos debe disponerse una triangulación horizontal que materialice la rigidez.

\section{Edificio Concordia de apartamentos Colonia}

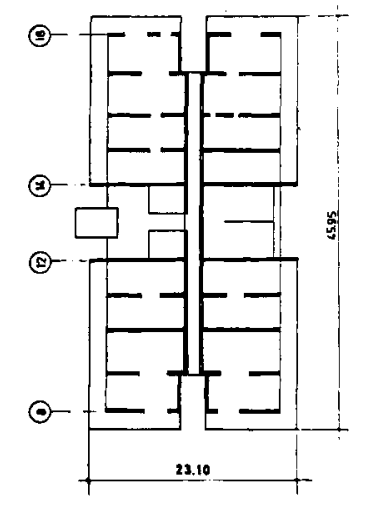

Planta tipo

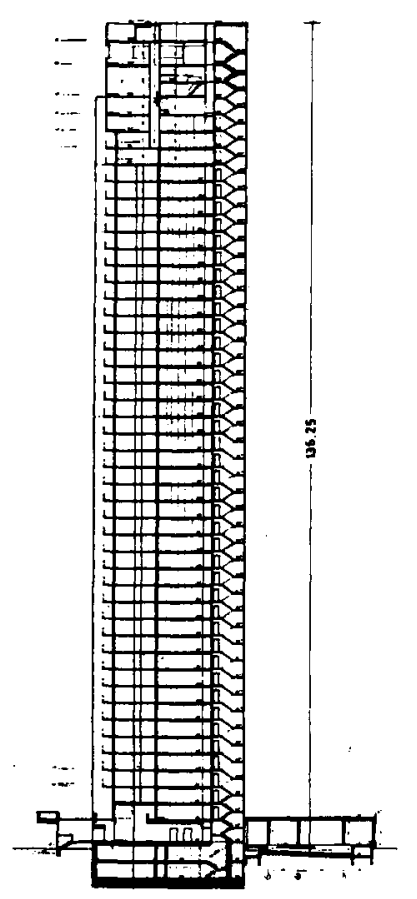


10

La distribución en planta de las pantallas viene determinada, además, por el hecho de que el forjado le transmita la suficiente cantidad de carga vertical que permita estabilizar en cimentación la carga horizontal que recoge.

Las pantallas suelen ser de hormigón o metálicas. Si son de hormigón se pueden utilizar con forjados del mismo material o metálicos. Es más raro utilizar forjados de hormigón con pantallas metálicas.

La utilización exclusiva de pantallas condiciona mucho el uso del edificio, por lo que se adoptan en aquellos casos en que los programas funcionales sean muy fijos como edificios de viviendas $u$ hoteles. El edificio de oficinas tiene unos programas más complejos, que se acoplan mal a la rigidez de un sistema de pantallas. En la figura 3 representamos un edificio alto en el que las pantallas desarrollan toda la función portante en una distribución ortogonal. En la figura 4 representamos el uso mucho más libre de las pantallas en Torres Blancas, edificio de viviendas de 26 plantas en Madrid.

En ambos casos la rígida distribución de pantallas choca con las necesidades funcionales en la planta baja. En el caso de Torres Blancas se procedió a eliminar alguna de las pantallas en su parte inferior sustituyéndola por pilares en sus extremos.

Es necesario tener en cuenta, en este caso, las trayectorias tensionales, verticales y horizontales, que se producen en la parte inferior de estas pantallas $y$ que nos permite realizar un armado adecuado.
Torres Blancas:

Arq.: Francisco Javier Sáinz de Oiza

Ings.: Carlos Fernández Casado y Javier Manterola

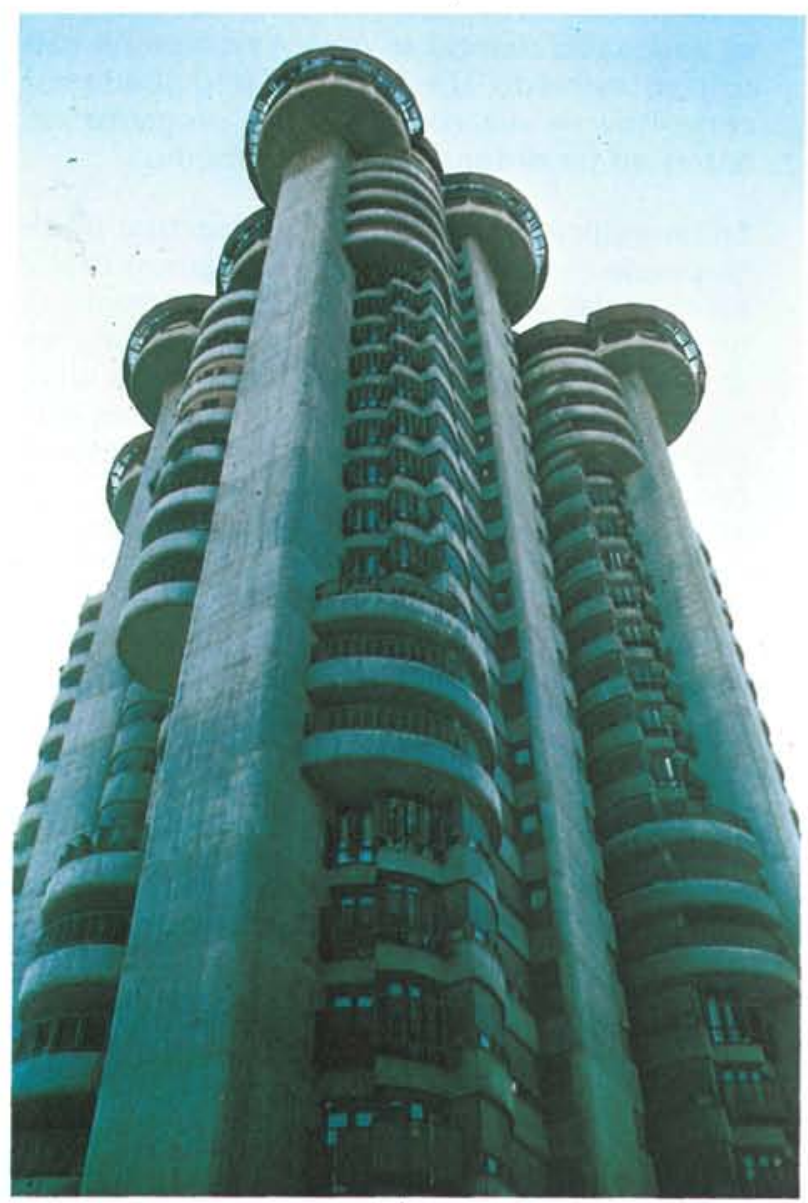

\section{Sección}

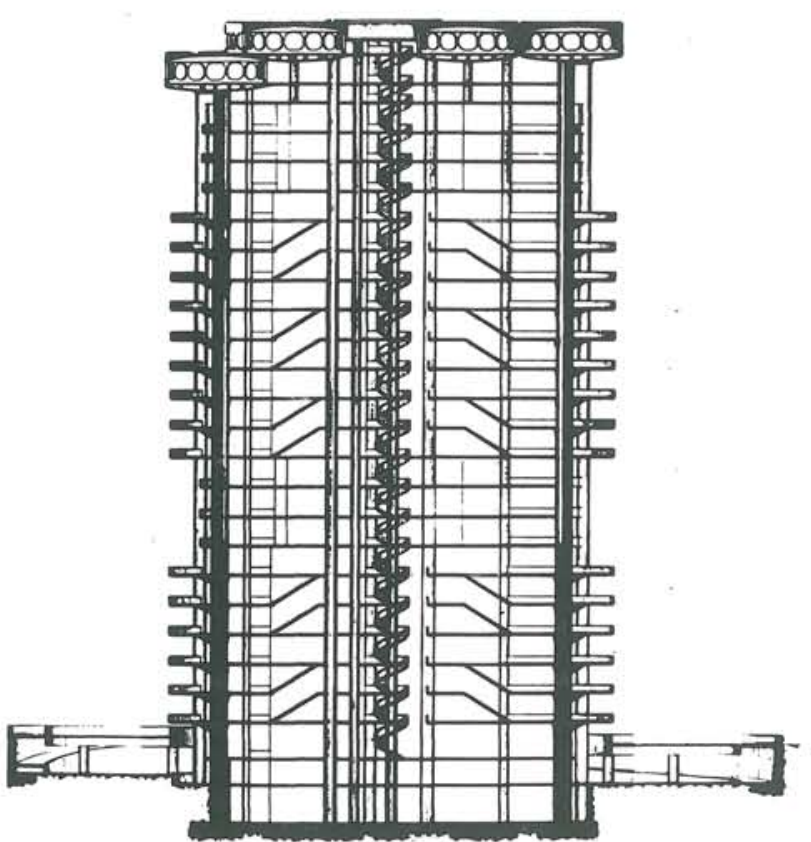

FIGURA 4

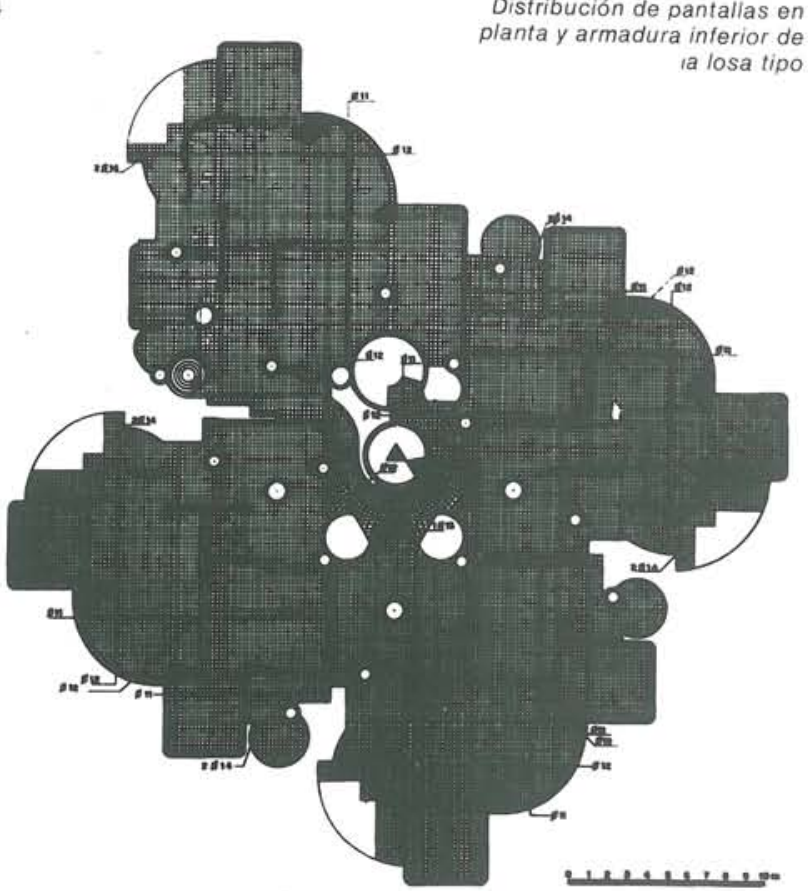


La estabilidad del edificio no se puso en peligro en Torres Blancas, pues el número de pantallas eliminadas fue pequeño. En otros casos es un problema a considerar con cuidado.

En edificios metálicos las pantallas se forman triangulando los pórticos de la estructura, es decir, eliminando la deformación por cortante que veíamos en 4.1. En la figura 5 se representan la planta y secciones de un edificio metálico de viviendas de 31 plantas. Se disponen dos pantallas trianguladas transversales y una longitudinal (sección b-b y línea continua gruesa en la planta) y cuatro pórticos: dos longitudinales y dos transversales (sección a-a y línea discontinua gruesa en planta), que completan el arriostramiento a torsión del edificio.

En otrcs edificios metálicos la pantalla contraviento se realiza rigidizando un pórtico metálico por chapas, hasta constituir una viga de alma llena, sin olvidar en ellos la rigidización contra la abolladura. Más frecuente es, sin embargo, realizar las pantallas de hormigón armado y el resto de la estructura metálica.

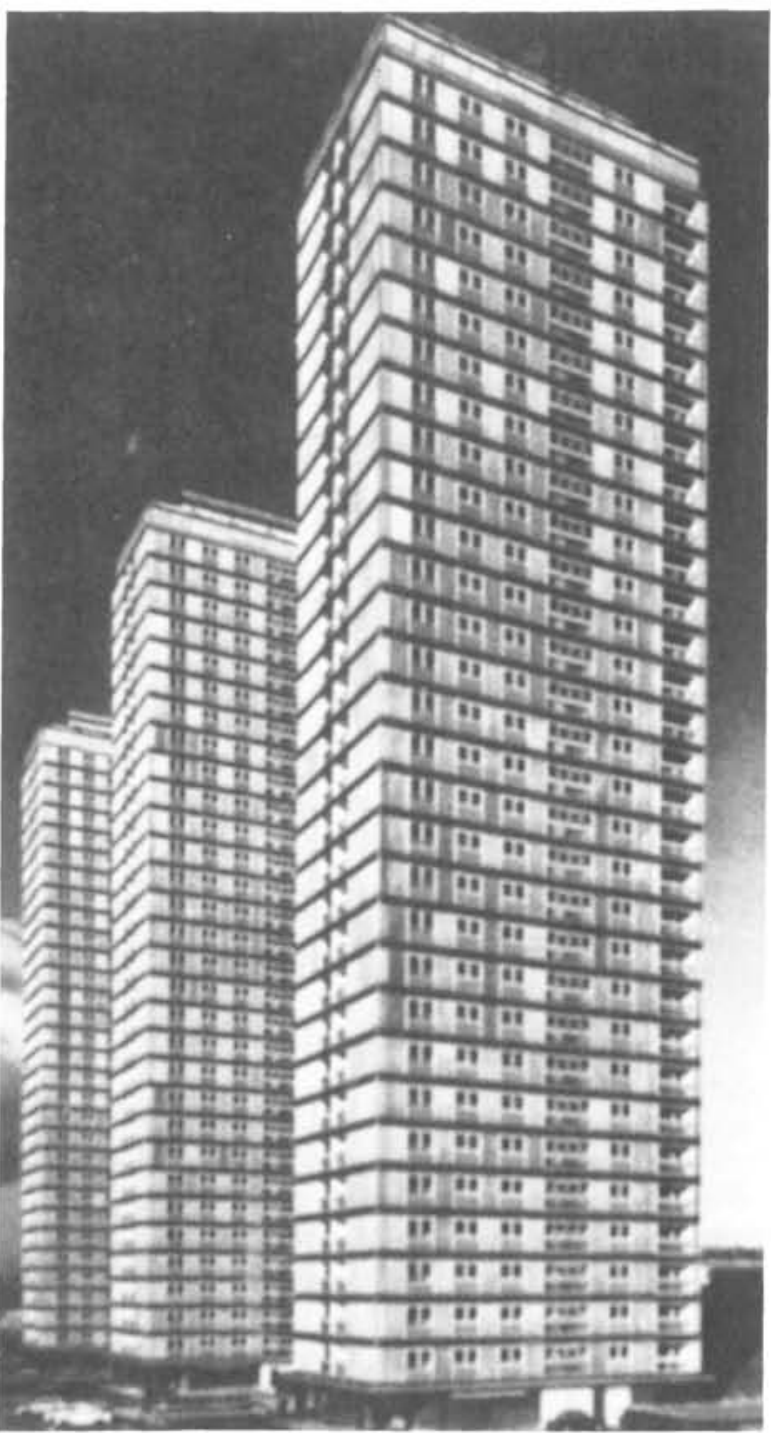

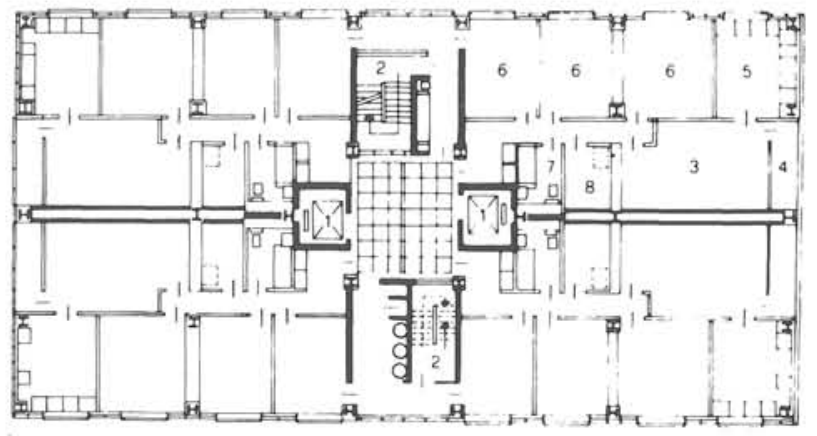

Planta tipo

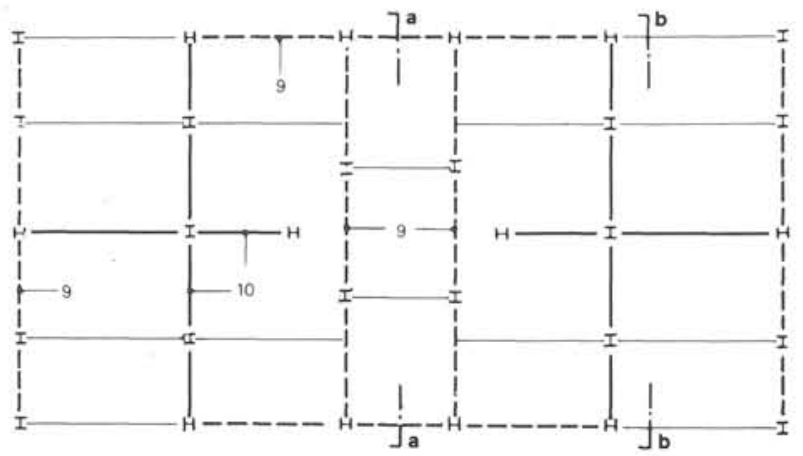

Distribución de pórticos y pantallas en planta tipo
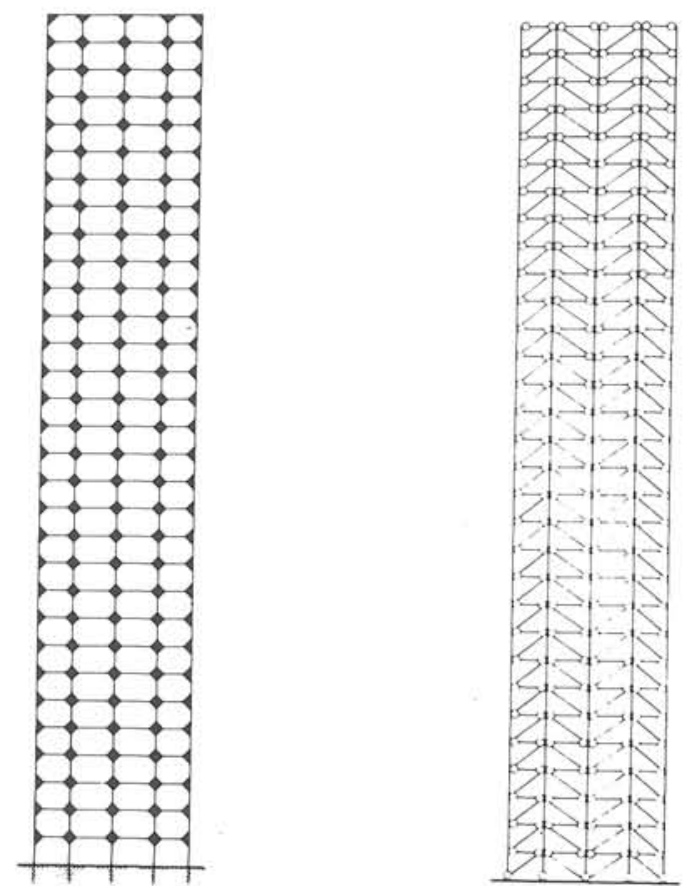

Sección a-a
Sección b-b 


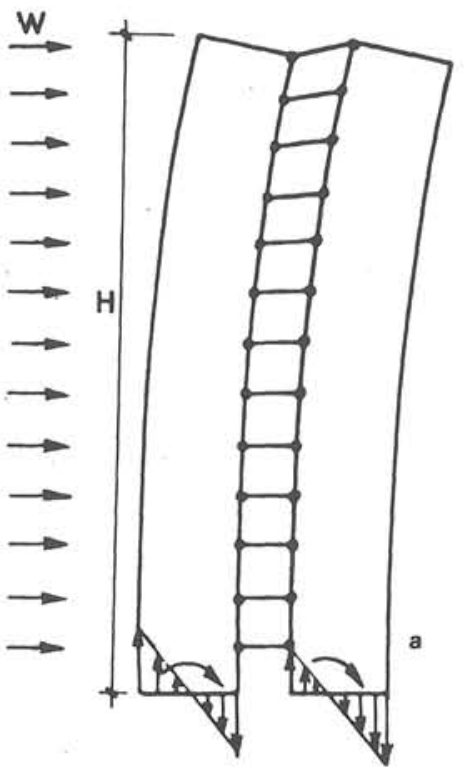

Generalmente en estos edificios las pantallas pueden disponer de puertas de paso. La pantalla se convierte entonces en un sistema de dos pantallas acopladas por un tejido de vigas (Fig. 6). Si la vinculación de las vigas con las pantallas es articulada, las dos pantallas se reparten la carga de viento en función de sus rigideces respectivas (Fig. 6.a). Si, como es lo más frecuente, las vigas se empotran en las pantallas se desarrollarán en ellas cortantes y flectores de signo contrario. El estado tensional de las pantallas se reduce, estableciéndose un estado de tensiones intermedio entre el que se produce en las dos pantallas separadas y el que se produciría suponiendo que las dos forman una unidad. Las vigas hacen el papel de un tejido a cortante bastante deformable (Fig. 6.b). En la figura 6.e representamos la ley de momentos de las cargas horizontales de la ménsula libre 1 y la que adquieren las pantallas acopladas 2, que puede ser un tercio de la anterior. En la figura 6.d representamos una típica ley de momentos de empotramiento en el tejido de vigas que cosen entre sí las pantallas. Esta ley de momentos crece de arriba a abajo de la pantalla para después reducirse cuando se hace presente el empotramiento de la pantalla en cimentación.

Su análisis resistente está perfectamente determinado y se utilizan principalmente dos métodos:

- El primero, desarrollado y tabulado por Rosman en 1966, consiste en sustituir el sistema discreto de vigas por un medio continuo de la misma rigidez. Suponiendo el punto de inflexión de la deformada en el centro de las vigas, las condiciones de compatibilidad y equilibrio dan lugar a una ecuación diferencial de segundo orden perfectamente resuelta.
Llamando $M_{1}$ y $M_{2}$ los momentos flectores que solicitan a cada una de las dos pantallas y $\mathrm{N}$ el esfuerzo axil y $\mathrm{M}$ al momento total exterior, queda:

$$
M=\frac{1}{2} w(H-x)^{2}=M_{1}+M_{2}+N \cdot \ell
$$

La ecuación diferencial que resuelve el sistema es:

$$
\frac{d^{2} N}{d x^{2}}-\alpha^{2} N=-\gamma^{2} M
$$

donde:

$\gamma^{2}=\frac{12 I_{v} \cdot \ell}{a^{3} h \cdot 1}$ y $\alpha^{2}=\gamma^{2}\left(\frac{A \cdot I}{A_{1} \cdot A_{2} \cdot \ell}+1\right)$

donde:

$I=I_{1}+I_{2}$ es la suma de las inercias de cada una de las pantallas.

$I_{v}$ es la inercia de la viga.

$A=A_{1}+A_{2}$ es la suma de las áreas de cada pantalla.

- El segundo procedimiento calcula el sistema como una estructura discreta (Fig. 6.c). Las pantallas se reproducen por su eje con su área e inercia, lo mismo que las vigas. La distancia entre el eje de las pantallas y el empotramiento de las vigas debe ser reproducido por barras de rigidez infinita. 


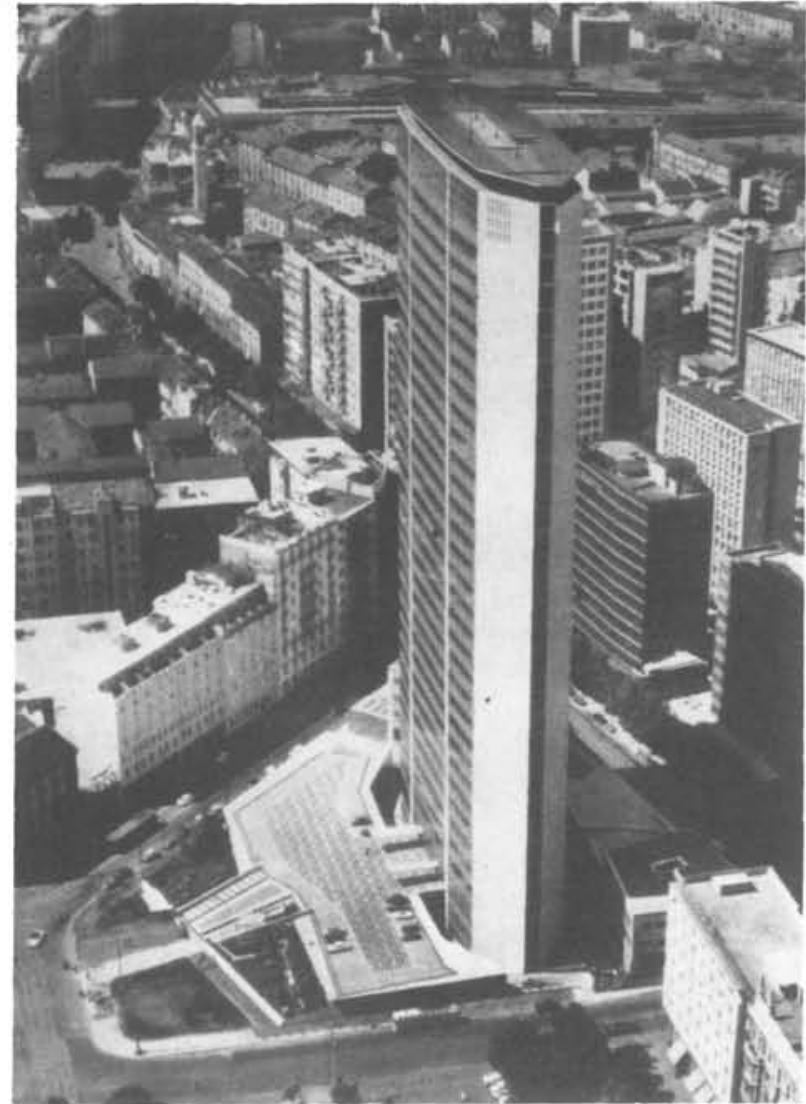

Un ejemplo notable del uso de pantallas internas acopladas lo tenemos en el edificio Pirelli de Milán, con proyecto de estructura de P. L. Nervi. Este edificio, de 35 plantas, $128 \mathrm{~m}$ de altura y una anchura reducida de unos $18 \mathrm{~m}$, está sostenido por un par de pantallas transversales y dos núcleos extremos. La estructura transversal de las plantas está dispuesta de manera que toda la carga del edificio va a las pantallas, estabilizándolas y pretensándolas (Fig. 7),

Cuando las pantallas no ocupan toda la planta del edificio, sino que están localizadas en zonas, suelen trabajar acopladas con los pórticos normales del edificio (Fig. 8.a). Si ambos elementos trabajasen por separado la pantallas adoptaría la deformación típica por flexión, mientras que en el pórtico predominaría la deformación por cortante (Fig. 8.b). En su trabajo conjunto se produce una deformación con un punto de inflexión bastante arriba, lo que determina que la pantalla se apoya en el pórti$\mathrm{co}$, en la parte superior, mientras que en la parte inferior es el pórtico el que se apoya en la pantalla. El punto de inflexión de la deformada separa ambas zonas (Fig. 8.C).

Uno y otro elemento colaboran juntos en la resistencia de las acciones horizontales $y$, aunque la rigidez de la pantalla suele ser mucho mayor que la del pórtico, y por tanto se lleva gran parte de la

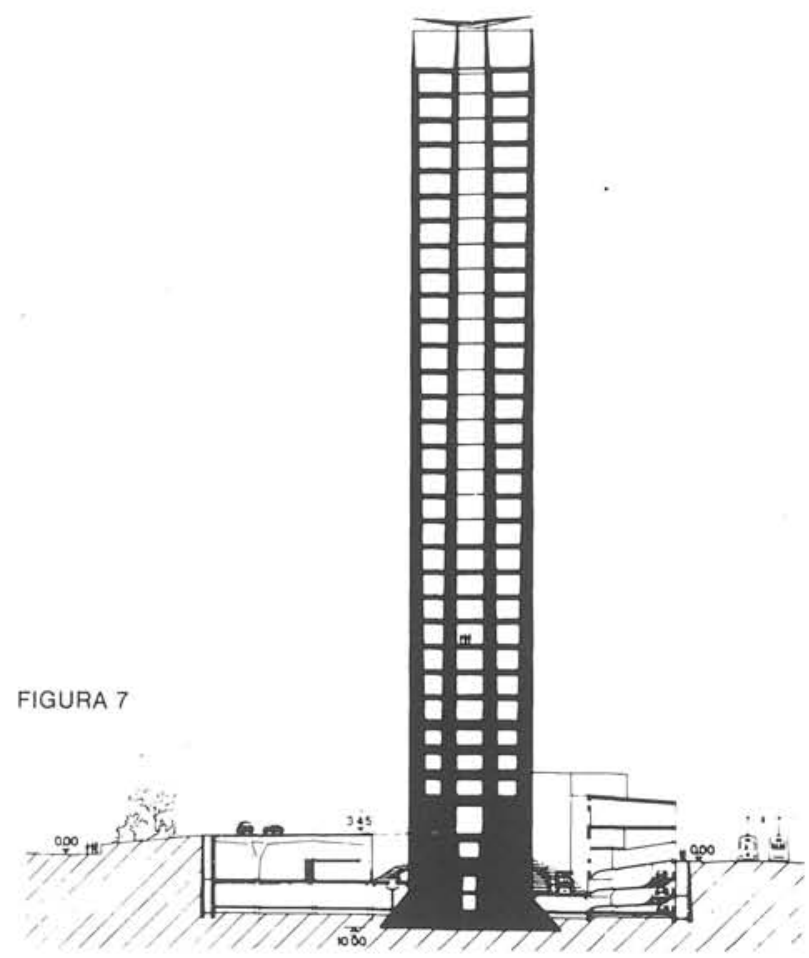

Sección

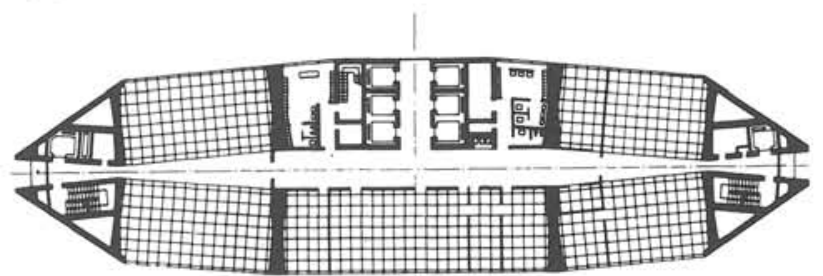

Planta

carga, no es correcto calcular ésta como si se llevase toda la carga horizontal, pues aunque se esté del lado de la seguridad en el empotramiento en el suelo de la pantalla, se está del lado de la inseguridad en el pórtico $y$, sobre todo, en las vigas que unen ambos elementos.

Como en el caso anterior se han desarrollado dos procedimientos de cálculo: uno continuo y otro discreto.

En el procedimiento continuo se sustituye la pantalla y el pórtico por su ecuación de equilibrio correspondiente:

$$
\begin{aligned}
& \text { - pantalla (en flexión) } E \cdot I \frac{d^{4} y}{d x^{4}}=w_{1}(x) \\
& \text { - pórtico (cortante) - G } \cdot A \frac{d^{2} y}{d x^{2}}=w_{2}(x)
\end{aligned}
$$

donde $\mathrm{E} \cdot$ I es la rigidez de la pantalla; $\mathrm{G} \cdot \mathrm{A}$ es la rigidez equivalente del pórtico múltiple (según hemos visto en 4.1.), y $w_{1}$ y $w_{2}$ la cantidad de carga exterior recogida por cada uno de los dos elementos. 


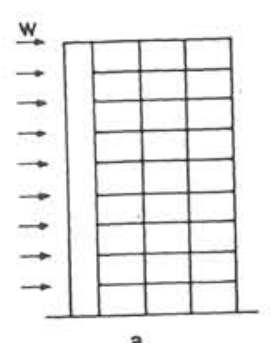

a
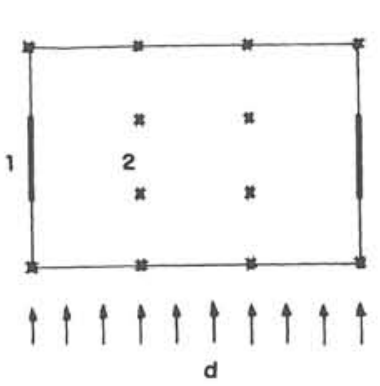

FIGURA 8

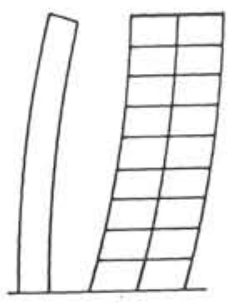

b

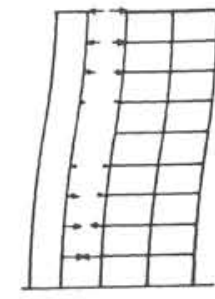

La ecuación diferencial que gobierna el problema es:

$$
\frac{d^{4} y}{d x^{4}}-\bar{\alpha}^{2} \frac{d^{2} y}{d x^{2}}=\frac{w}{E \cdot 1}
$$

donde:

$$
\bar{\alpha}^{2}=\frac{G \cdot A}{E \cdot I}
$$

y la solución de la ecuación para w constante:

$$
\begin{gathered}
y=\frac{1}{8} \cdot \frac{w \cdot H^{4}}{E \cdot I} \cdot \frac{8}{\alpha^{4}}\left[\frac{\alpha \operatorname{sh} \alpha+1}{\operatorname{ch} \alpha}(\operatorname{ch} \alpha z-1)-\right. \\
\left.; \quad-\alpha \operatorname{sh} \alpha z+\alpha^{2}\left(z-\frac{1}{2} z^{2}\right)\right]
\end{gathered}
$$

donde:

$$
\alpha=\bar{\alpha} H z=\frac{x}{H}
$$

El segundo discreto, es similar al indicado en el caso de las dos pantallas acopladas, pero aplicado a esta nueva tipología.

Los procedimientos discretos tienen la ventaja de que el cálculo puede extenderse con facilidad al edificio completo. Por ejemplo, el edificio simétri- co de la figura 8.d, formado por dos pórticos simples 2, y otros dos constituidos por pantallas con pórtico incorporado 1 , se puede calcular como un pórtico plano (Fig. 8.e), sin más que ponerlos en serie, interponiendo entre ellos unas vigas biarticuladas que igualan los corrimientos entre ambos. EI oficio de las vigas biarticuladas lo desarrolla, en el edificio real, la planta que suele considerarse indeformable.

En este tipo de edificios conviene cuidar la situación de las pantallas, que tienden a desplazarse hacia las fachadas para que perturben poco la distribución funcional y, entonces, pueden quedar poco cargadas axilmente siendo los que más carga horizontal recogen.
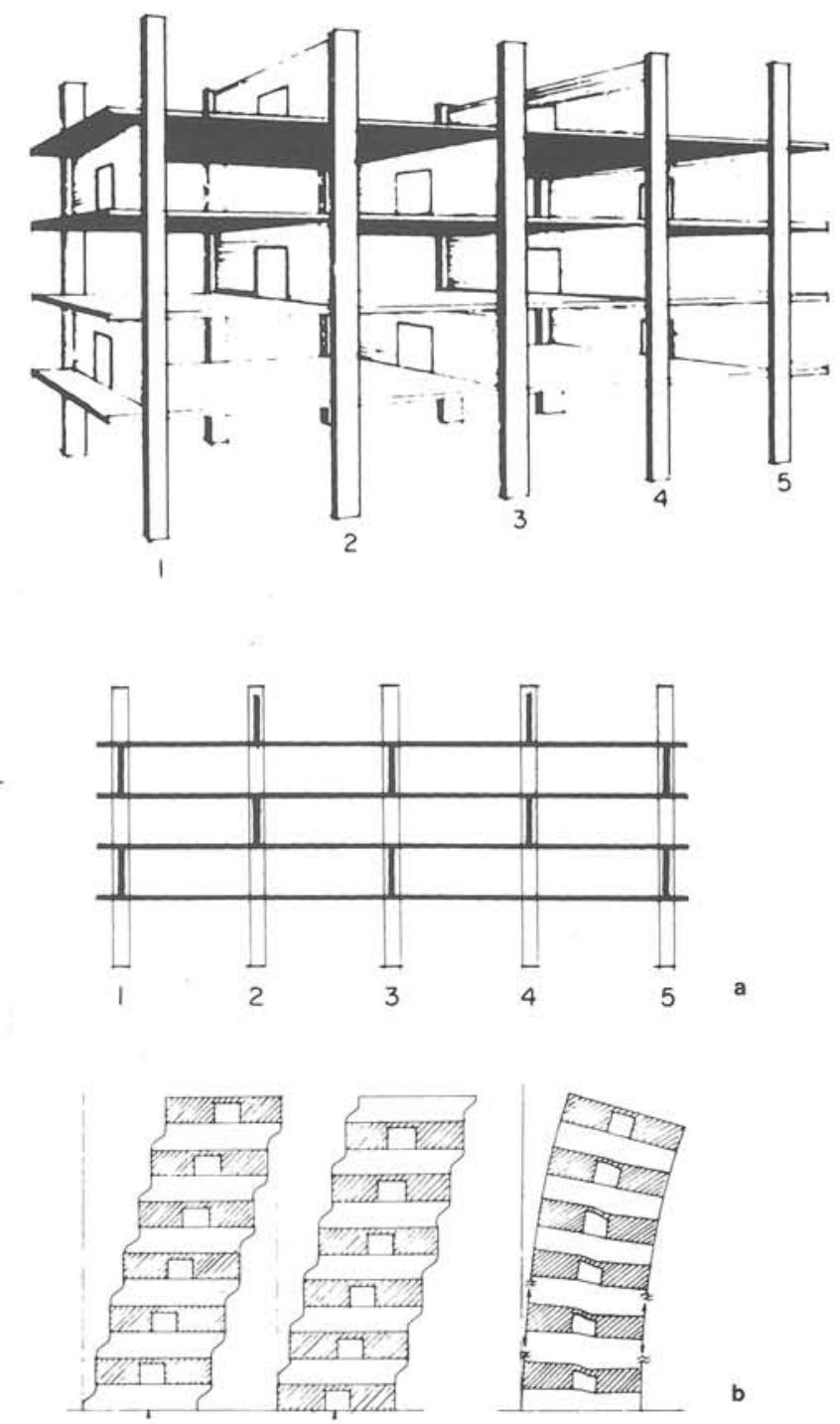

FIGURA 9 
Por último conviene reseñar el método de las pantallas interrumpidas alternativamente (Staggered wall-beam system), desarrollado en 1960 en USA (Fig. 9). En este procedimiento las pantallas puentean el edificio de lado a lado, soportando a la vez el forjado superior e inferior disponiéndolos una planta sí y otra no, alternándolas en planos transversales contiguos.

La finalidad de esta extraña disposición es proporcionar una cierta flexibilidad a la distribución funcional de plantas de apartamentos.

Su respuesta ante las acciones horizontales se representa en la figura 9.b y se basa en la actuación de las losas de piso que deben funcionar como diafragmas continuos transmitiendo el cortante almacenado en una columna de pantallas discontinuas a las contiguas.

Si consideramos que cada columna de pantallas discontinuas trabajasen independientemente, se produciría un gran desplazamiento horizontal entre los distintos pisos como consecuencia de la deformabilidad de las columnas laterales sometidas a fuertes cargas de corte. Dado que en la pantalla contigua se produce el mismo efecto, pero desplazado una altura, las losas de piso se verían deformadas. Como la hipótesis de indeformabilidad en su plano de las losas de pisos es correcta, su papel consiste en recoger el cortante, que iba a deformar a las pilas verticales transmitiéndola a las pantallas contiguas. La deformación conjunta de las pantallas alternadas será muy similar a la que se produciría si la pantalla fuese continua.

\subsection{Núcleo resistente}

El núcleo resistente constituye un caso particular de las estructuras formadas por pantallas. La pantalla se pliega formando una viga cajón de gran rigidez a flexión y torsión. Esta solución es propia, principalmente, de los edificios de oficina. El núcleo se sitúa en el centro del edificio y en su interior se alojan los ascensores, escaleras y servicios. A él se le destina la carga vertical y horizontal del edificio.

La necesaria penetración en el interior del núcleo obliga a perforar sus paredes, lo que introduce en el núcleo una deformación por cortante complementaria controlada por la rigidez a flexión de las vigas que las unen entre sí. Si el dimensionamiento de estas vigas es suficientemente grande y la relación altura-anchura del núcleo también -lo que suele ocurrir casi siempre en los edificios altos-, el estado tensional vertical coincide bastante bien con la teoría de la viga y con la deformación plana de las secciones $y$, por lo tanto, la eficacia resisten-
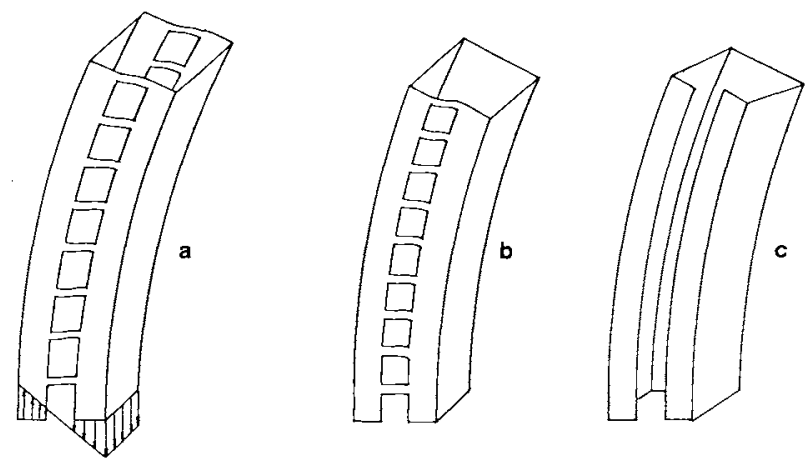

FIGURA 10

te del núcleo ante las acciones horizontales es muy grande (Fig. 10.a).

Las penetraciones reducen mucho más la rigidez a torsión del núcleo si lo comparamos con la que tendría de no existir éstas. Este hecho determina la necesidad de centrar el núcleo en la planta para evitar solicitaciones torsoras complementarias y la necesidad de que su superficie, comparada con la de la planta, sea suficientemente grande.

La forma de los núcleos es muy diversa y viene gobernada por las necesidades de los elementos de elevación del edificio. Pueden ser cajones unicelulares y pluricelulares, rectangulares, curvos, etcétera.

El análisis de los núcleos resistentes debe realizarse por la teoría de las vigas cajón, en la que se tiene en cuenta el alabeo torsional con paredes perforadas. El método de los elementos finitos es particularmente preciso, en estos casos, para tener en cuenta todos los fenómenos resistentes que hemos señalado. En ningún caso debe tenerse en cuenta la distorsión - deformación de la sección transversalpor estar claramente arriostrado por la losa de piso que lo rodea.

Un ejemplo perfecto de edificios soportados por el núcleo central exclusivamente lo constituyen aquellos que utilizan grandes plataformas, que recogiendo toda la carga de las plantas del edificio, la transmiten al núcleo central. La misión funcional de estas plataformas es liberar a la planta inferior $y / o$ a las plantas intermedias de la presencia de los pilares periféricos. Dentro de ellos se pueden distinguir los edificios colgados y los apoyados.

En la figura 11 se representan las Torres de Colón, en Madrid, edificio de 31 plantas de las cuales las 20 superiores están colgadas de una plataforma rígida dispuesta en la planta superior. Las plantas de hormigón, con dimensiones pequeñas en planta $19,4 \times 17,4 \mathrm{~m}$, se apoyan por un lado en el núcleo 
central de $7 \times 6,9 \mathrm{~m}$, y por otro cuelgan de 18 tirantes de hormigón pretensado (Fig. 11).

El núcleo central está muy comprimido a lo largo de toda su altura, pues una parte de las cargas de peso propio y uso de las plantas se dirigen al núcleo, y otras ascienden por los tirantes hasta la parte superior del mismo para bajar por él. Por esta razón el núcleo está muy bien conformado para resistir los efectos del viento.

El problema resistente específico de los edificios colgados lo constituye la desnivelación de apoyos

\section{Torres Colón:}

Arq.: Antonio Lamela

Ings.: Carlos Fernández Casado, Javier Manterola, Leonardo Fernández Troyano y Emilio Salaverri.
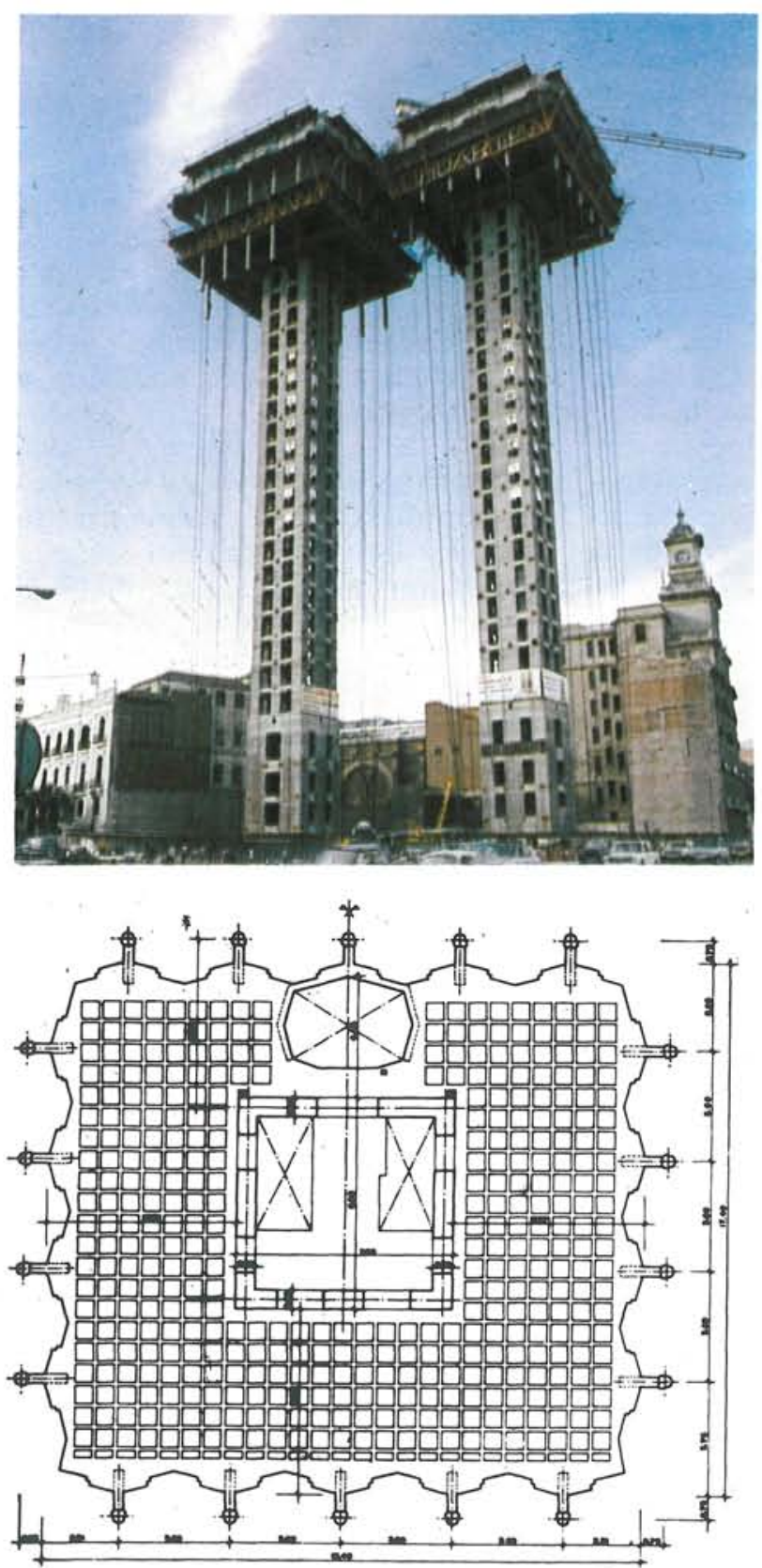

que existe en cualquier piso entre las zonas apoyadas en el núcleo, y las que cuelgan de los tirantes.

Esta desnivelación se debe a que las zonas unidas al núcleo experimentan un descenso correspondiente al acortamiento del núcleo desde la cimentación hasta la losa que consideremos, mientras que los puntos unidos a los tirantes descienden lo correspondiente a la altura total del núcleo más el alargamiento de los tirantes desde la parte superior de la torre a la planta en cuestión, más las flechas que experimentan las plataformas. En estos alargamientos hay que considerar no sólo los elásticos debidos a la carga, sino también los correspondientes a la temperatura, la fluencia y la retracción.

La desnivelación es tanto más importante cuanto más baja sea la planta en consideración y cuanto mayor sea el número de plantas.

Existe, además, otro factor de principal importancia que es la relación existente entre la anchura y la altura del edificio. Se entiende que cuanto menos alto y más ancho sea el edificio, mejor se adapta la solución colgada a la idoneidad estructural, mientras que si se trata de un edificio alto y estrecho puede darse el caso de que la deformación diferencial señalada anteriormente sea tan importante que el efecto de soporte de los tirantes exteriores desaparezca - a efectos prácticos- y las plantas de pi-

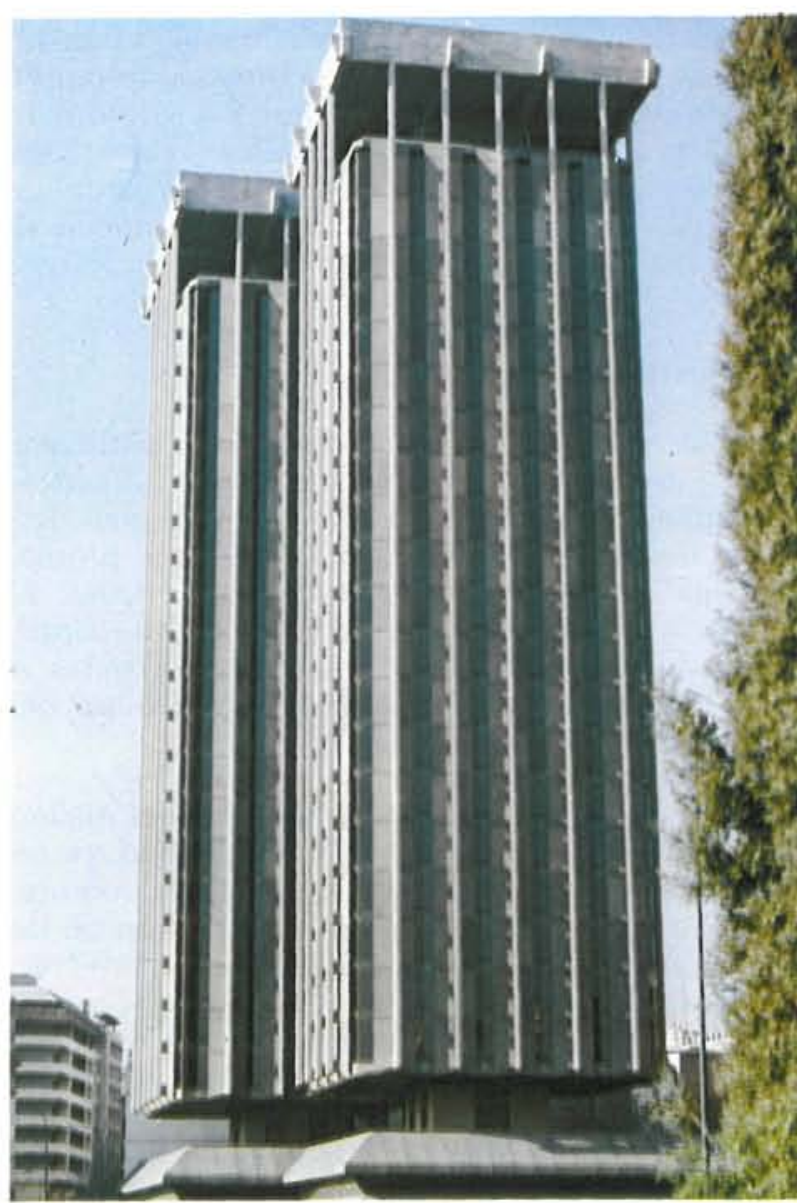


so se comporten como si estuviesen en voladizo desde el núcleo.

Esta problemática desemboca en dos preguntas: ¿cuál debe ser el número de plantas colgadas de una sola plataforma? y iqué material debe utilizarse en los tirantes?

En Torres Colón se presentan las condiciones más desfavorables para un edificio colgado; se trata de un edificio alto y estrecho, con veinte plantas colgadas. La adopción de tirantes de hormigón pretensado tiene muchas ventajas. No responde ante la carga pasivamente, como les ocurre a los tirantes metálicos, sino que es un soporte activo. El pretensado introduce una deformación de acortamiento que elimina la desnivelación de carga permanente e incluso puede promediarse la de sobrecarga.

Las deformaciones de fluencia y retracción van también en la dirección de reducir los asientos diferenciales. Tiene también más inercia térmica que los metálicos, con lo cual puede ser dejado al exterior.

En el Standard Bank de Johannesburg se utilizan también tirantes de hormigón pretensado, pero se disponen tres plataformas intermedias de las que se cuelga el edificio (Fig. 12). En este edificio se presentó un problema complementario. El pretensado longitudinal de las plataformas de hormigón pretensado, con sus deformaciones, producían un
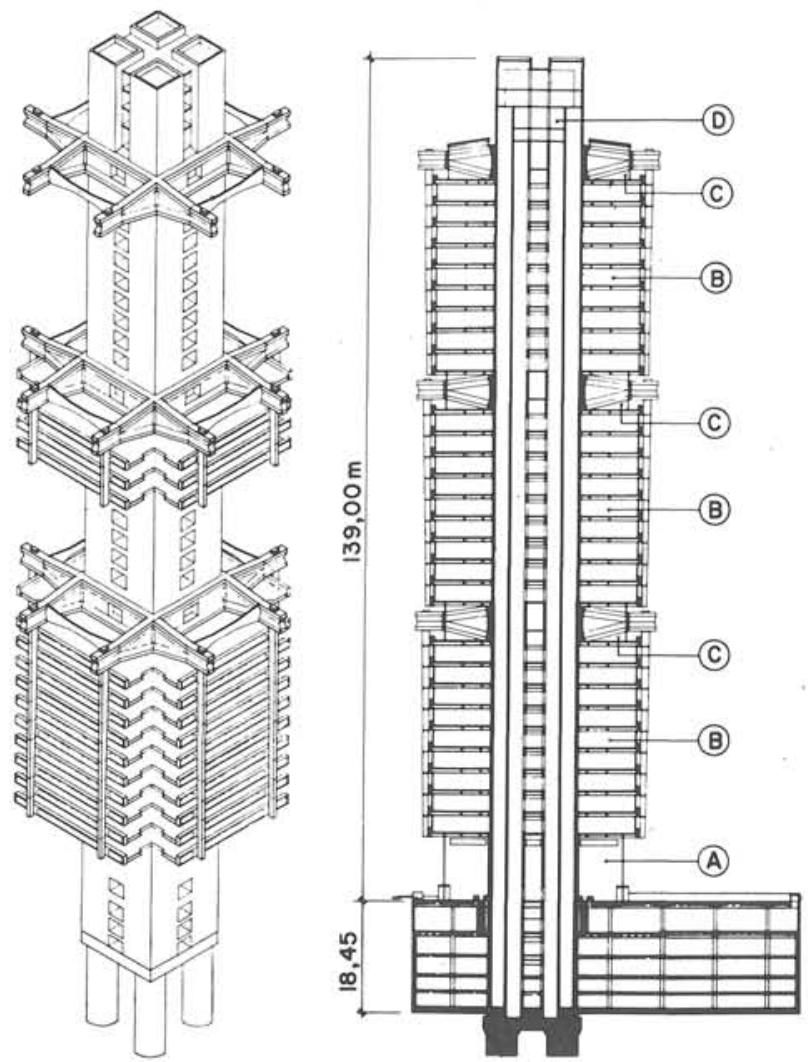

acortamiento axil significativo de las mismas. Como la planta colgada inmediatamente inferior no tiene estos acortamientos axiles, el tirante que los une - de gran dimensión transversal- se ve sometido a unas flexiones de eje horizontal inadmisibles, lo que obligó a colgar estas plantas de tirantes individuales más pequeños.

En Torres Colón este problema también se presentó, pero con un efecto mucho más pequeño. Se proporcionó una flexibilidad mayor a los tirantes por tres razones: su longitud es bastante grande, su inercia es muy pequeña $y$, además, se establece una articulación entre la plataforma superior y el tirante.
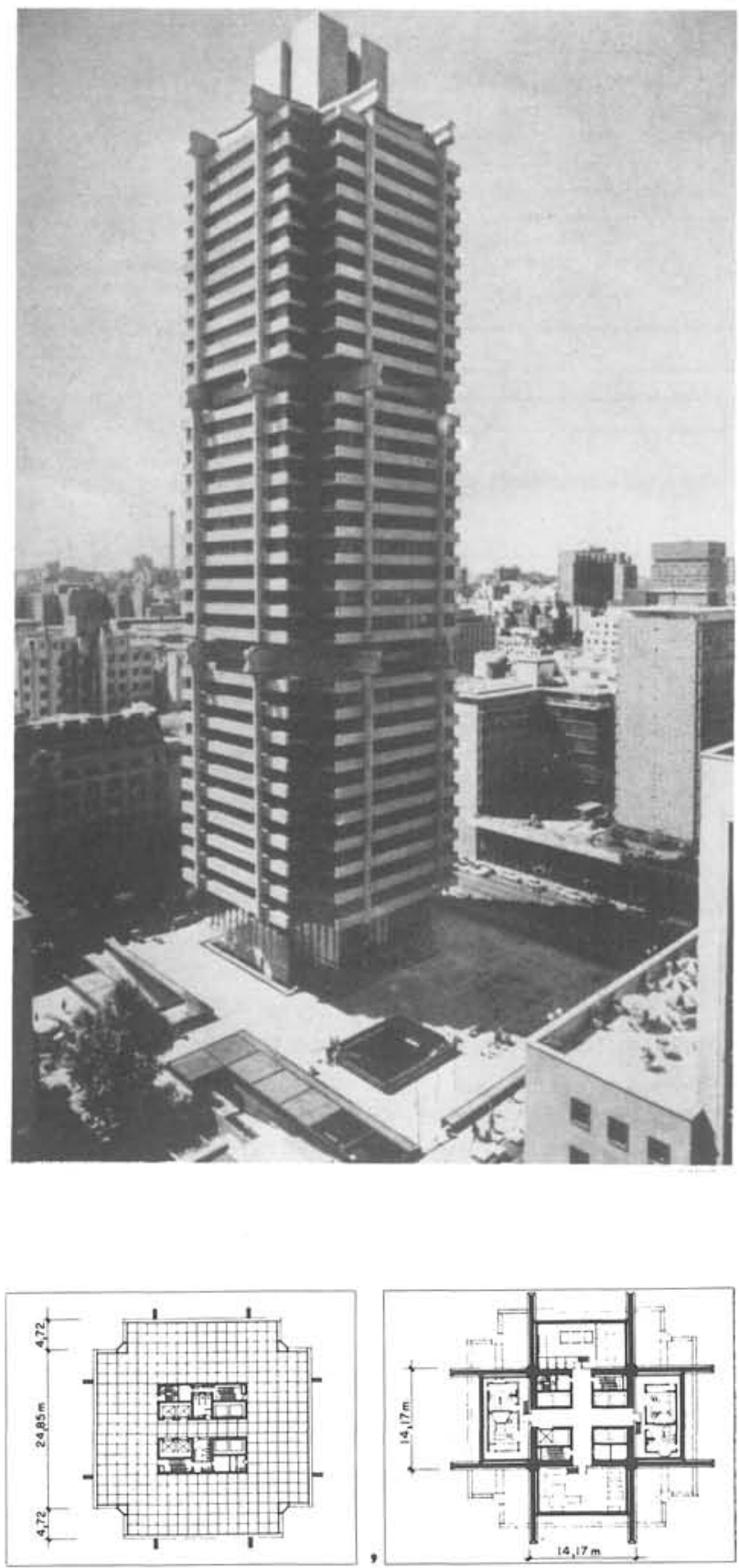

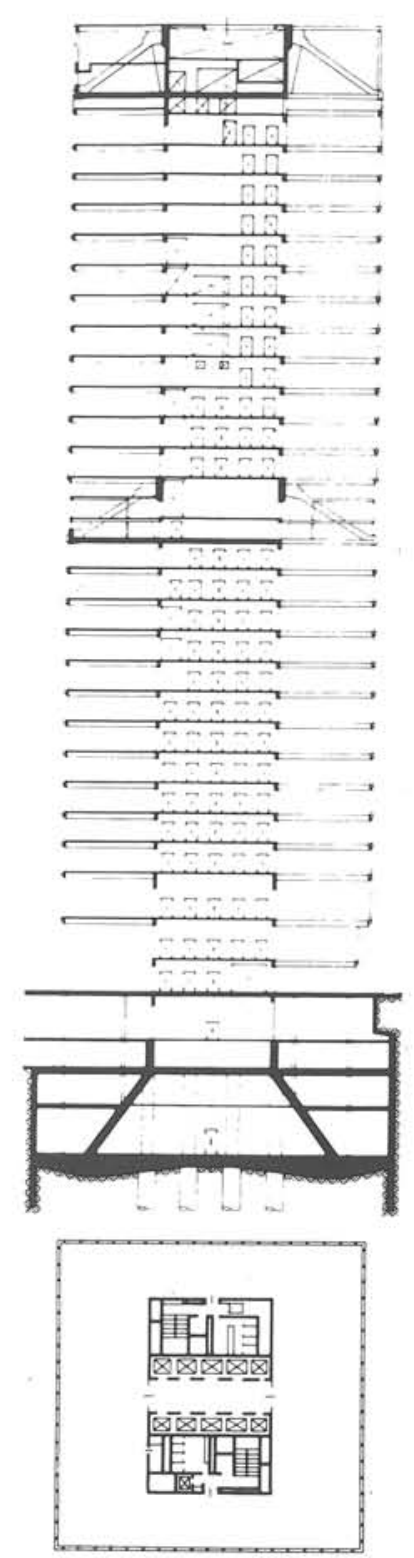

Sección vertical de la

estructura en voladizo
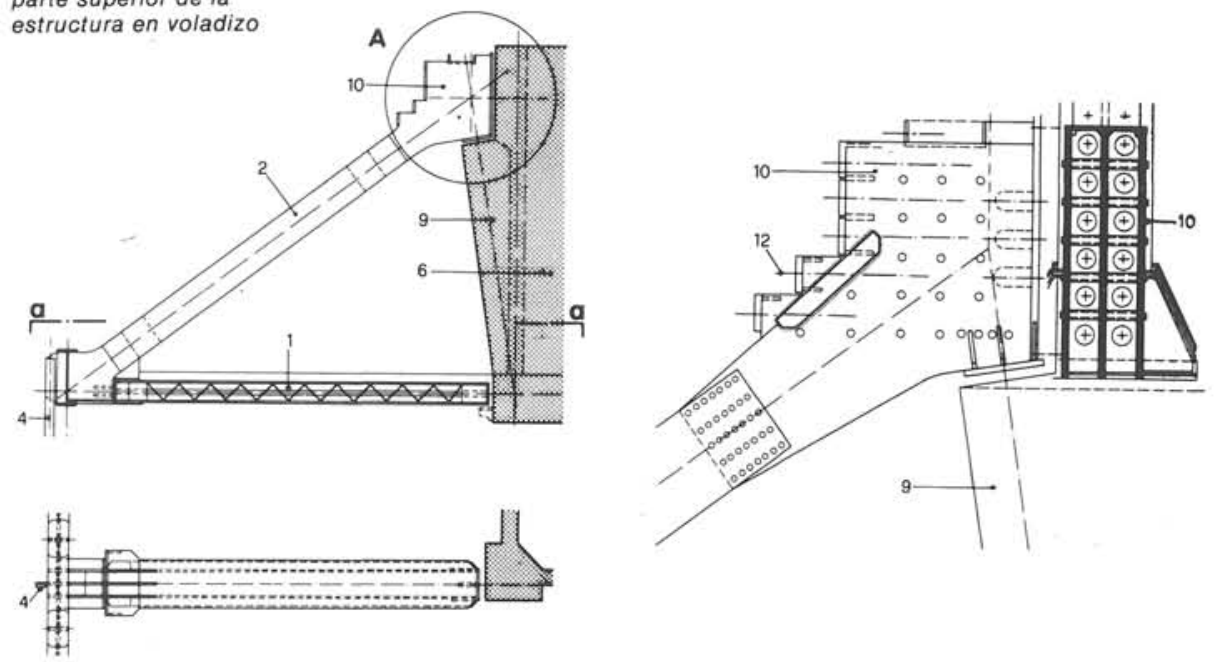

Fases de la construcción:

A Hormigonado de los pozos de cimentación y de una pared pantalla rodeando la futura fosa de cimentación.

B Hormigonado de una losa de arriostramiento y excavación de la fosa de cimentación interiormente a la pared pantalla.

C Elevación de las paredes del núcleo, construcción de una losa intermedia debajo de la losa de arriostramiento.

D Acabado del zócalo cónico y de la losa de cimentación tras la excavación completa de la fosa.

E Terminado el núcleo de hormigón, montaje de los forjados suspendidos exteriormente.
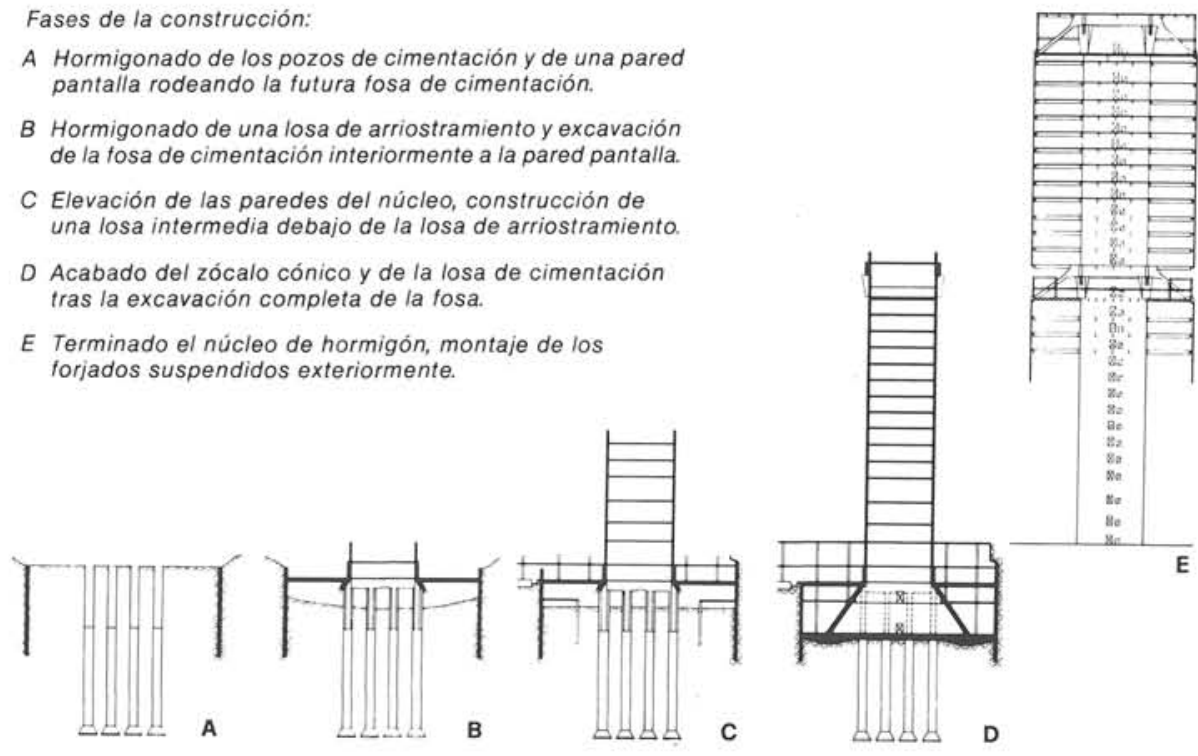

FIGURA 13
En el caso de edificios metálicos - con núcleo generalmente de hormigón- los tirantes suelen ser metálicos, formados por chapas planas de muy poca rigidez a la flexión, que suelen estar metidos dentro del cerramiento con el fin de aislarlos de las temperaturas exteriores (Fig. 13). La sustentación de la planta suele ser isostática, lo que la obliga a dos condiciones: apoyarse en el núcleo y romper la continuidad superficial que se establece alrededor del mismo. En este caso hay que controlar los corrimientos verticales totales en las plantas más bajas e incluso entre dos plantas sucesivas, lo que obliga a solicitar a los tirantes a tensiones muy bajas.

En este caso no se produce interacción resistente entre núcleo y tirantes ante los efectos de viento. En cambio, en el caso de edificios de hormigón, esta interacción existe, pues los giros diferenciales que se producen en el núcleo están coaccionados por los tirantes a través de la rigidez a flexión de las plantas de pisos. En la parte inferior es solamente el núcleo el que recibe toda la carga vertical y horizontal.

El mismo esquema estructural se puede plantear en edificio apoyado. La plataforma resistente se dispone a nivel de la primera planta y empotrada en el núcleo central; los tirantes se convierten en pilares y los problemas de desnivelación de apoyos se reducen drásticamente.

Vamos a comentar dos edificios altos que utilizan grandes plantaformas de hormigón pretensado para apoyar la estructura de pisos y puentearla entre varios núcleos: 

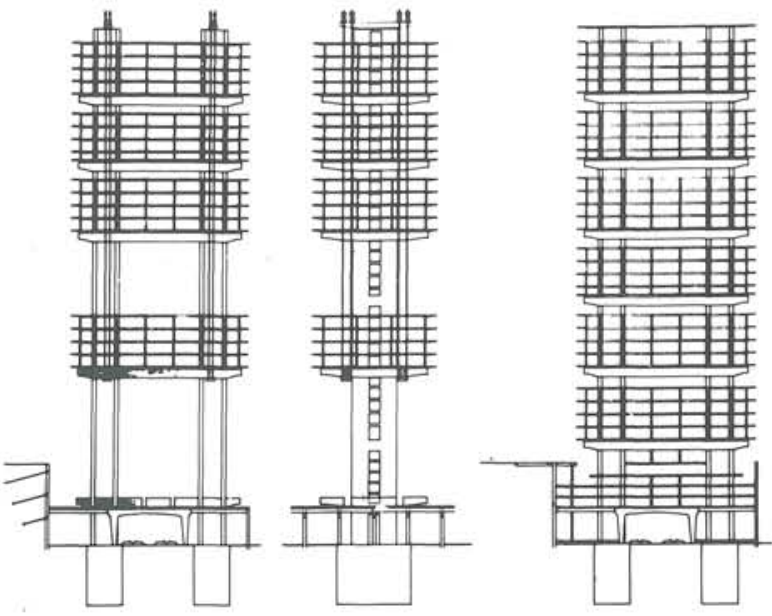

Secciones

Planta de estructura

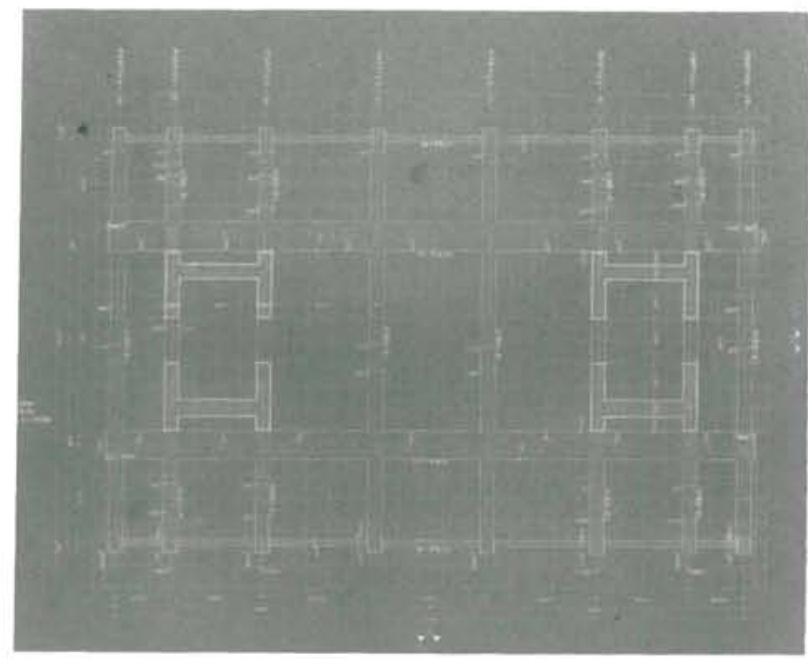

Banco de Bilbao:

Arq.: Francisco Javier Sáinz de Oiza.

Ings.: Carlos Fernández Casado, Javier Manterola y Leonardo Fernández Troyano.

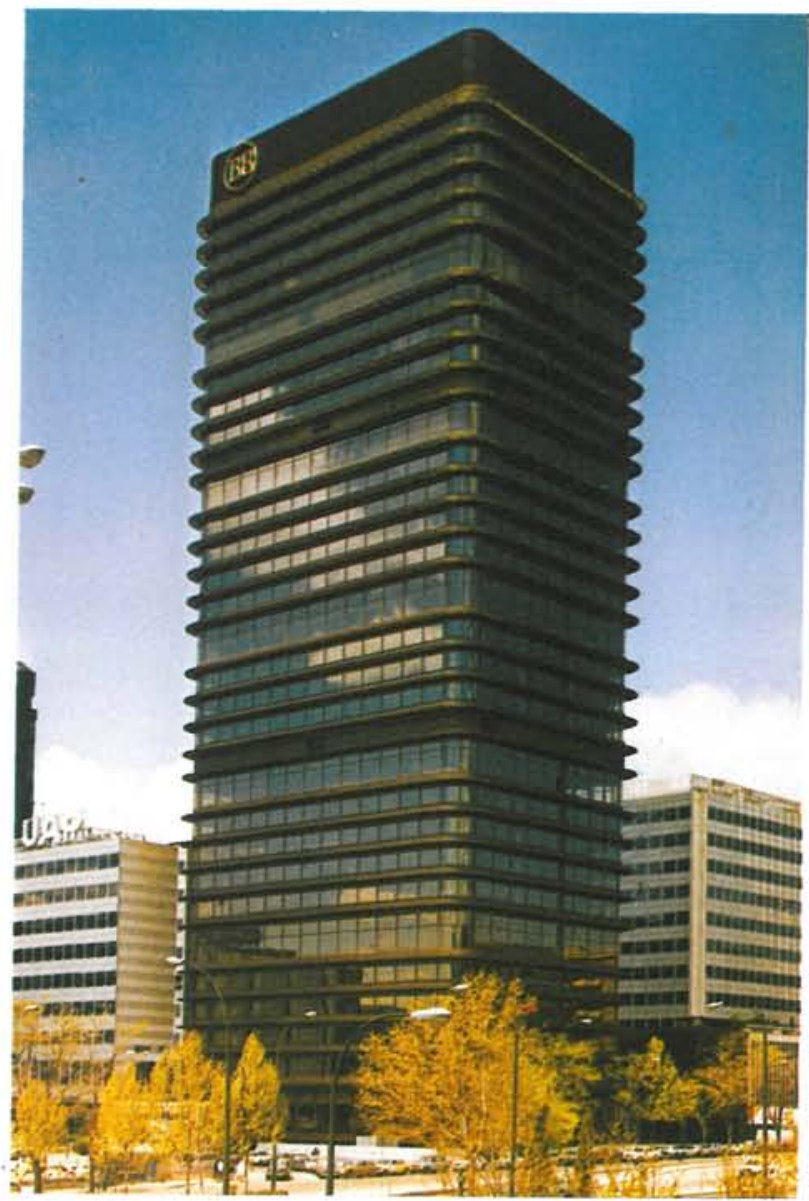

FIGURA 14

- El primero es el edificio del Banco de Bilbao en Madrid y el segundo es "U.N. City» en Viena. Ambos edificios se construyeron casi simultáneamente.

- El Banco de Bilbao (Fig. 14), tiene $116 \mathrm{~m}$ de altura y 36 plantas, de las cuales 30 , de $26 \times 39$, están apoyadas en dos núcleos de $9 \times 6,3$. Estos núcleos, separados entre sí $19 \mathrm{~m}$, se disponen a los lados de unas líneas de ferrocarril subterráneo situado bajo el edificio. Las 30 plantas superiores del edificio se dividen en 6 bloques de 5 plantas. Cada bloque está formado por una gran plantaforma de vigas de hormigón pretensado de $2 \mathrm{~m}$ de canto, que sostiene 5 plantas superiores en estructura metálica.

La misión de estas plataformas es doble. Puentear los $19 \mathrm{~m}$ de distancia entre los núcleos, per- mitiendo que las 5 plantas superiores tengan luces normales. En segundo lugar rigidizar los dos núcleos verticales hasta formar un gran pórtico con ellos, lo que reduce los esfuerzos producidos por el viento.

- El "U.N. City» de Viena es un conjunto de edificios de oficinas en "Y». Tienen $113 \mathrm{~m}$ de altura (Fig. 15). La estructura portante vertical está constituida por un núcleo central y tres núcleos $\in$ n los extremos de los brazos de la "Y». Entre ellos se disponen 3 plataformas de hormigón pretensado que sostienen cada una 5 niveles, salvo la más alta que sostiene 14 plantas.

De esta tipología de edificios existen bastantes realizaciones en el mundo. K. Roche, Kenzo Tange, etc., han realizado una serie de edificios basados 
en el mismo criterio: establecer una serie de núcleos bastante distanciados entre sí, sobre los que puentean una o unas grandes plataformas de hormigón pretensado, que soportan o cuelgan una serie de plantas con distancias entre pilares pequeños.
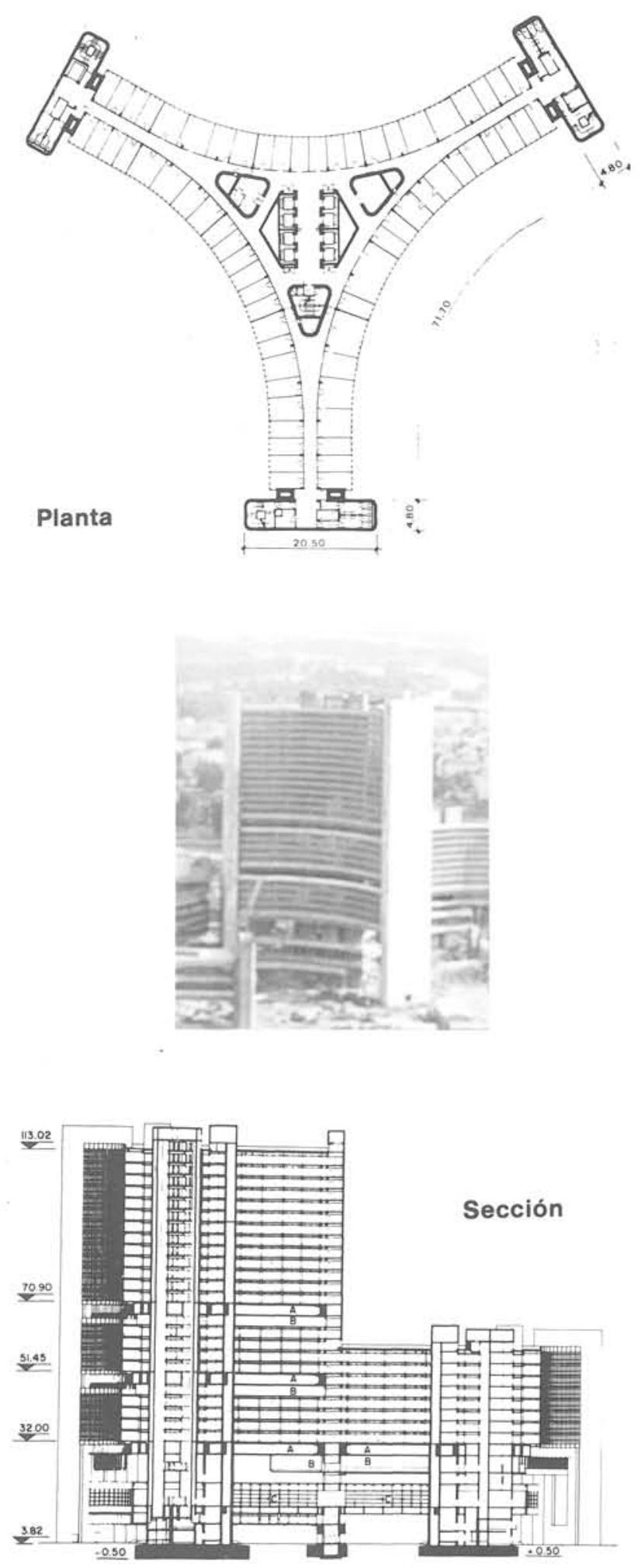

\subsection{Interacciones núcleo resistente-fachada}

Salvo el caso de los edificios colgados o apoyados, el núcleo central se ayuda de los pilares de borde en la resistencia a las acciones horizontales. Esta interacción entre ambos elementos se realiza a través de la rigidez a flexión de los forjados horizontales y su cuantía depende de la rigidez del propio núcleo, de la relación ancho-alto del edificio, del área de los pilares de contorno y de la rigidez de los forjados.

En la figura 16 representamos esta colaboración. Una parte del momento total de las acciones horizontales exteriores es recogida por el núcleo central y otra lo es por el par que se produce entre los pilares opuestos.

Si bien el mecanismo resistente de colaboración entre núcleo y pilares exteriores es el mismo que el analizado cuando examinábamos la colaboración

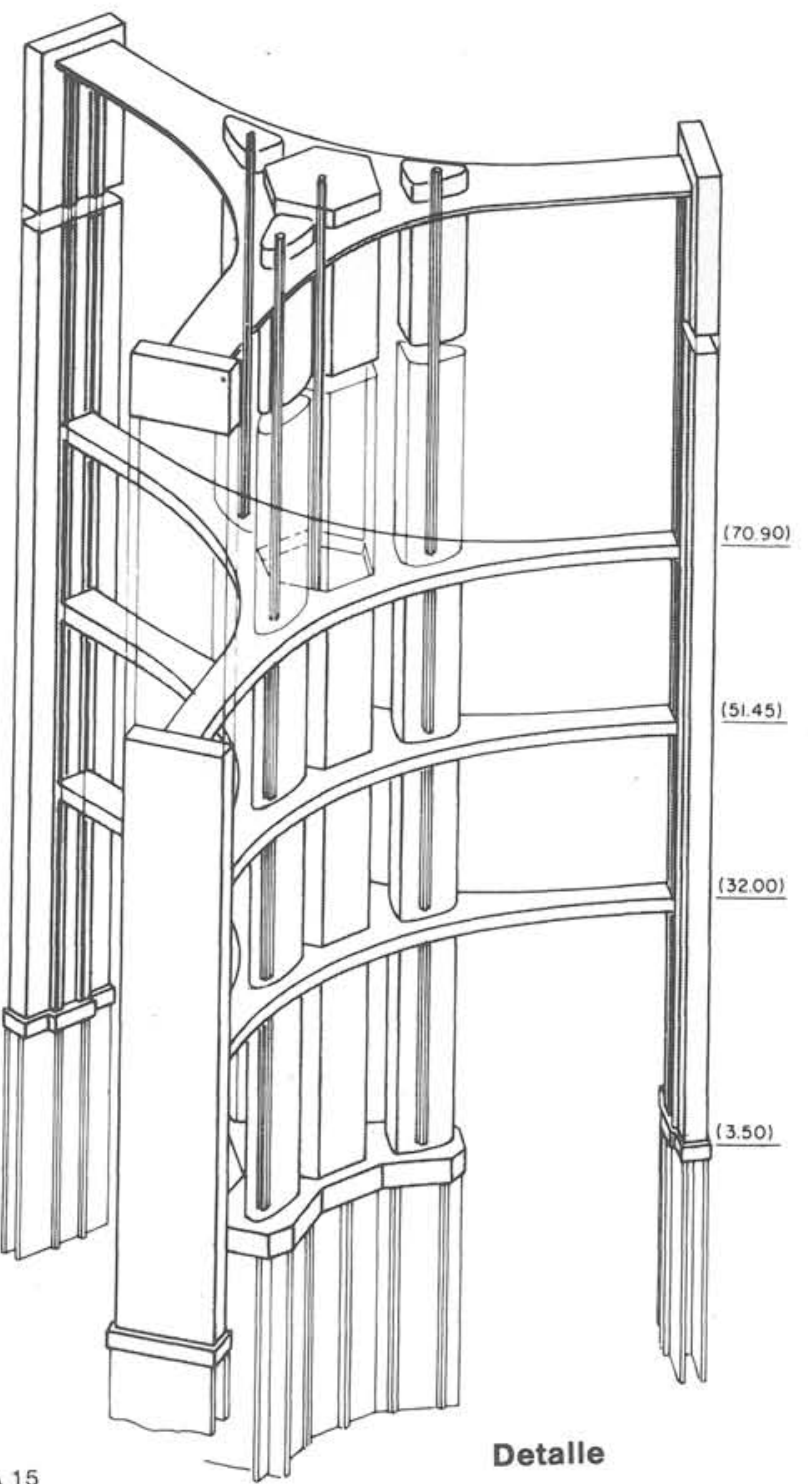



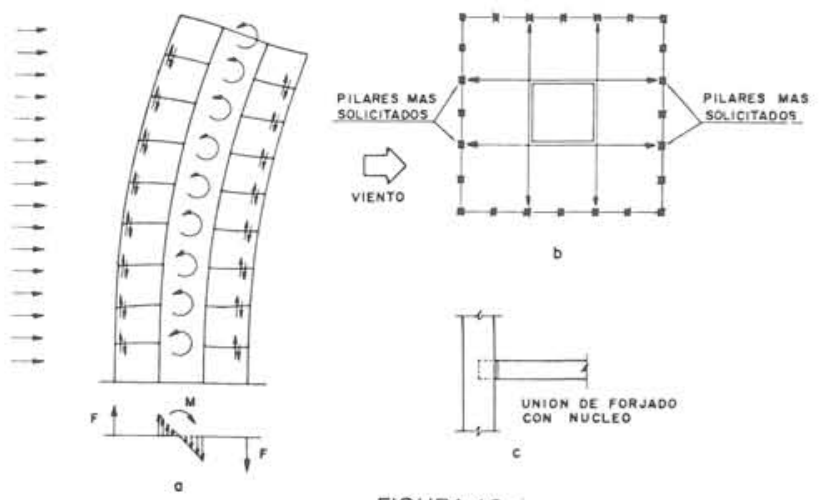

FIGURA 16

entre pantallas planas y pórticos adosados, o dos pantallas planas entre sí, en el caso de edificios con núcleo central el problema se complica por tratarse de un mecanismo espacial. Además, es frecuente que el forjado se articule sobre el núcleo, tanto si se utiliza forjado metálico como de hormigón. Por esta razón el empotramiento obligado entre forjado y núcleo, para que exista colaboración resisten-

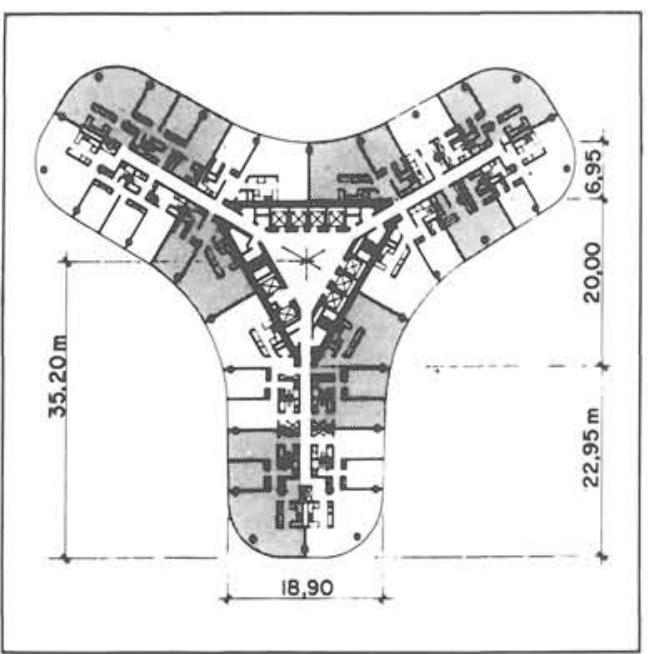

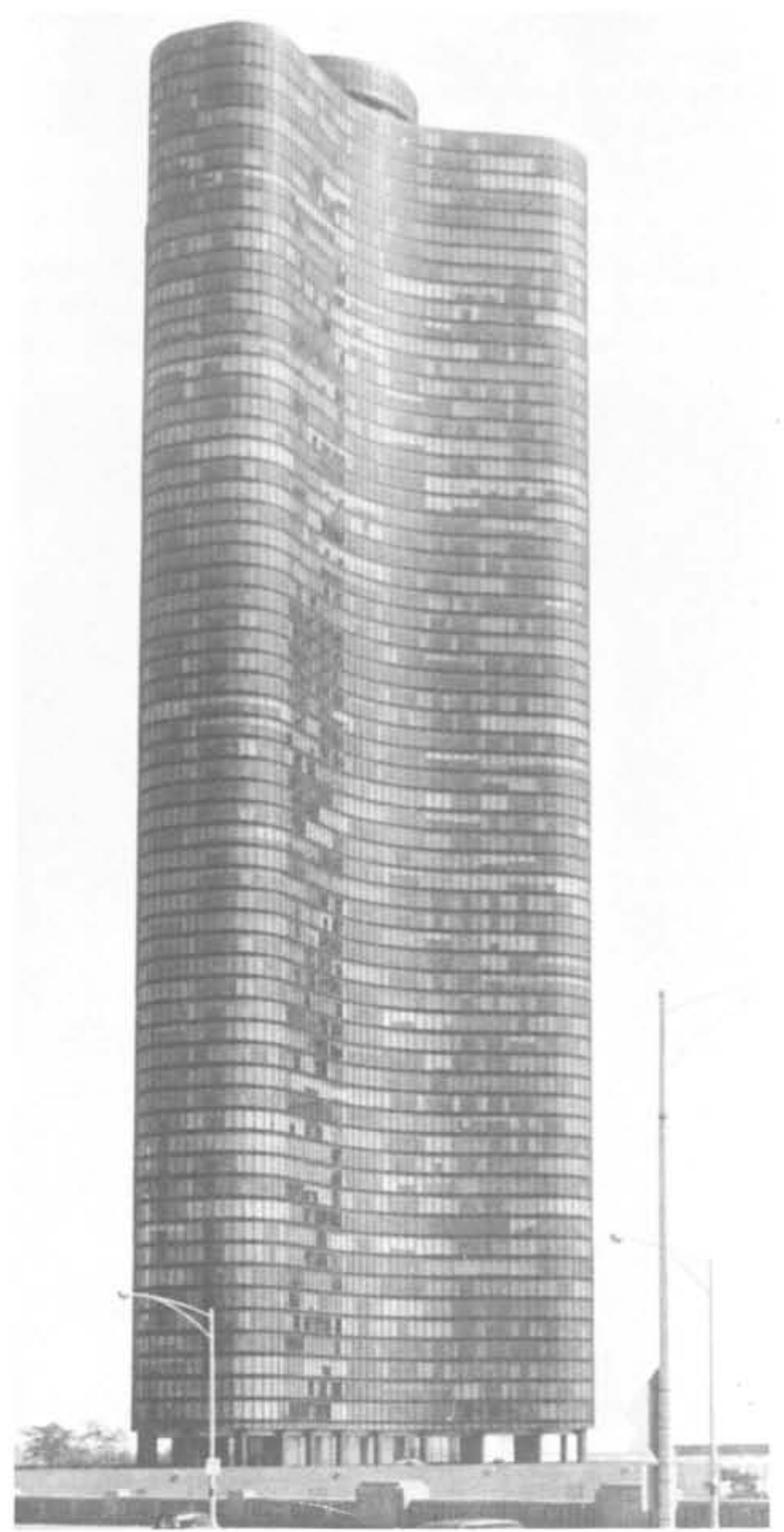

FIGURA 17

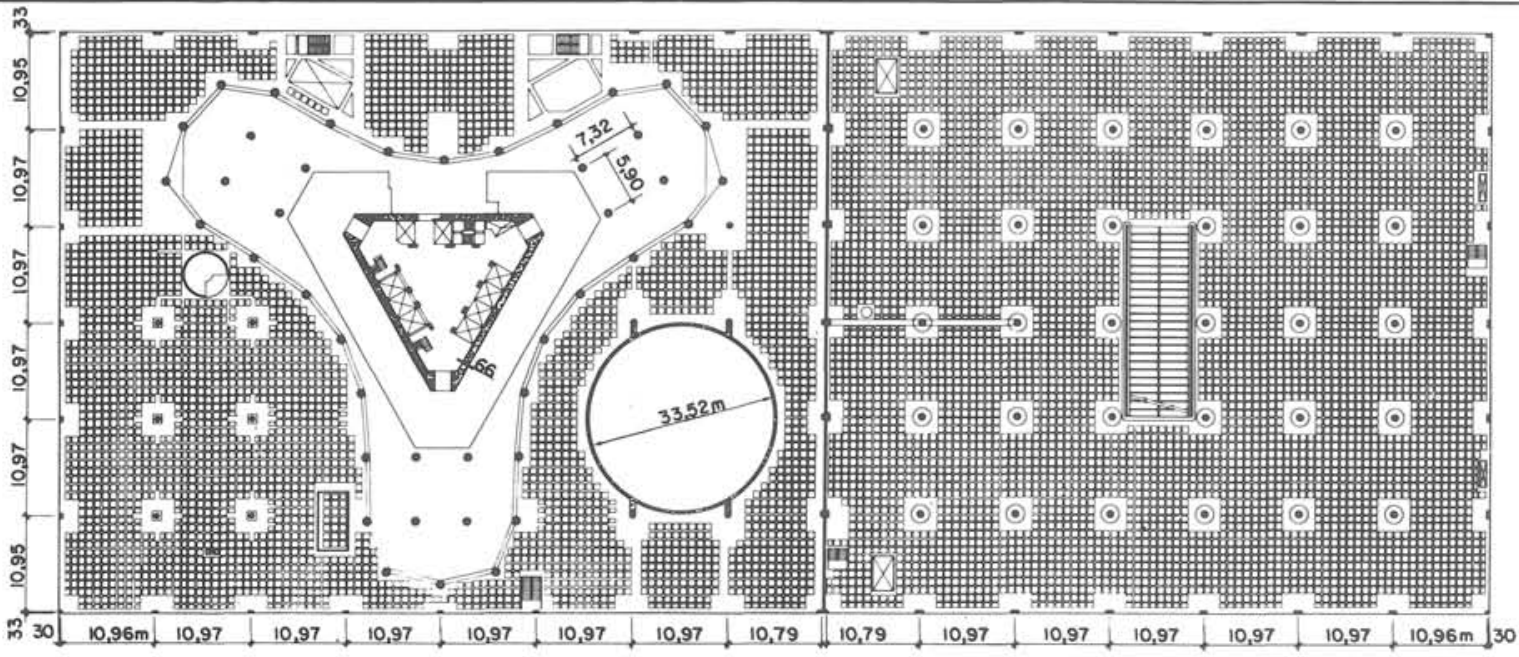


te con los pilares de fachada, sólo puede establecerse a través de franjas del forjado paralelas a los lados del núcleo y próximas a él (Fig. 16.b), donde la igualación de giros entre el núcleo y el forjado se verifica automáticamente.

Esta condición determina que no todos los pilares de contorno colaboran de la misma manera con el núcleo, sino que esta colaboración es mucho más
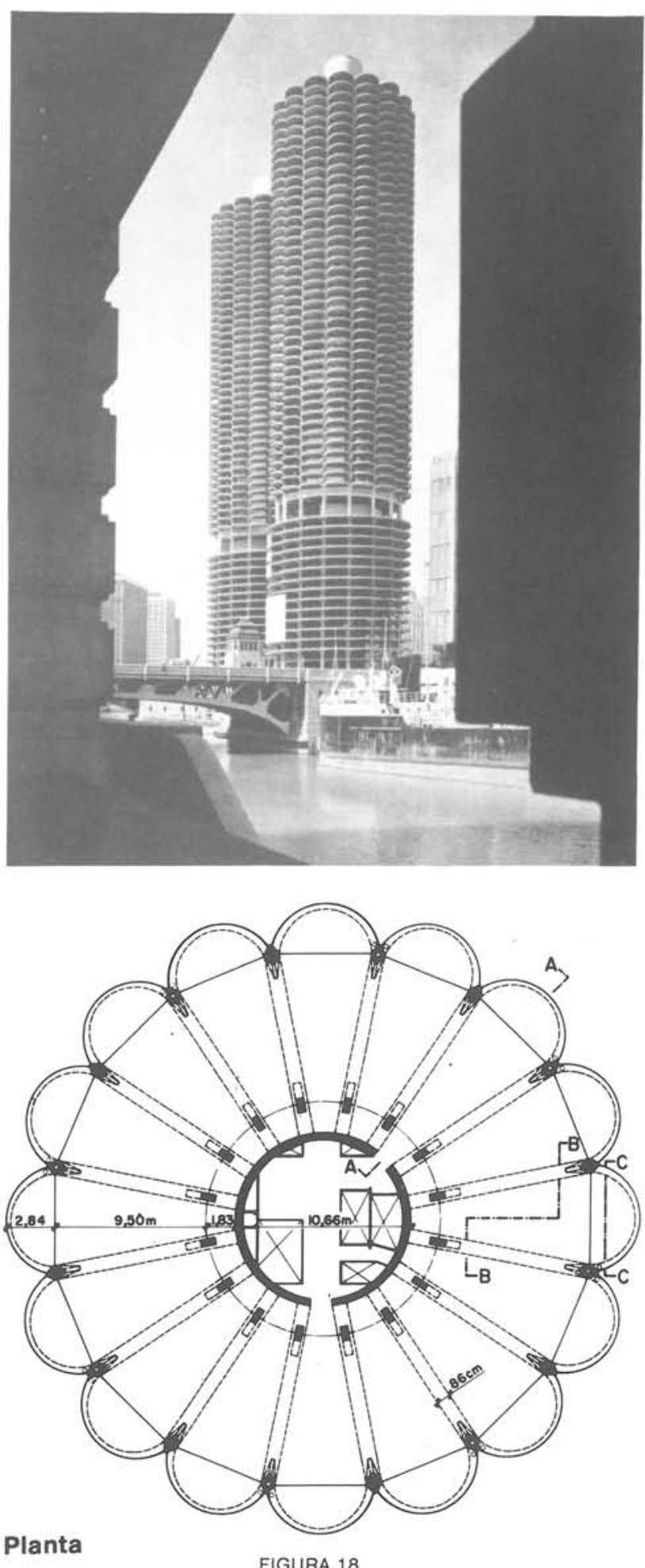

eficaz con los pilares enfrentados con las esquinas del núcleo (Fig. 16.b). La capacidad del forjado de transmitir carga al resto de los pilares viene disminuida por su flexibilidad transversal.

Veamos una serie de ejemplos de edificios en altura en los que la colaboración resistente entre el núcleo central y los pilares del contorno es creciente, por tratamiento especial de la rigidez de los forjados horizontales:
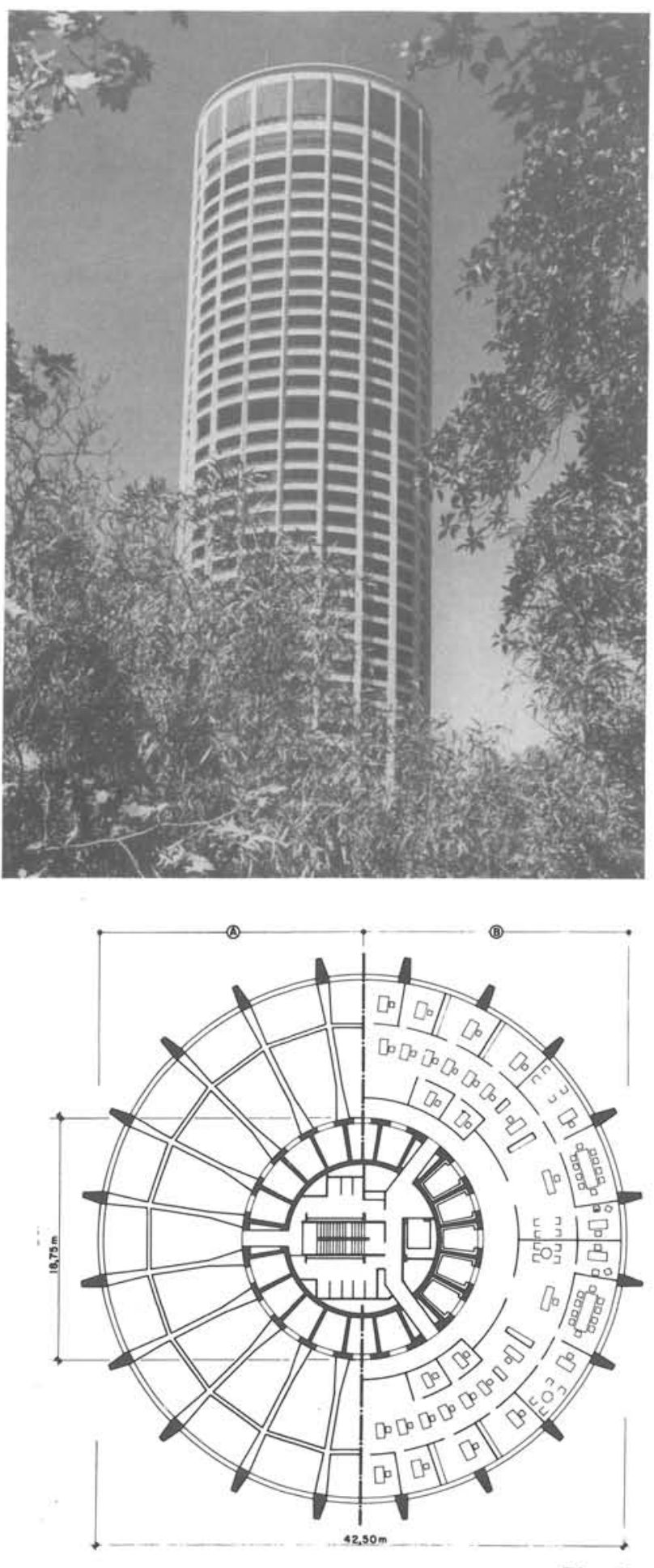

FIGURA 19 
- En la figura 17 representamos la torre «Lake Point», en Chicago, de 71 plantas y $195 \mathrm{~m}$ de altura. Consta de un gran núcleo central triangular de $20,8 \mathrm{~m}$ de lado que se eleva hasta el piso 58 $y$, a partir de este punto, el núcleo es sustituido por pilares. El núcleo es extraordinariamente rígido, mientras que el forjado formado por una losa de hormigón ligero de $20 \mathrm{~cm}$ de espesor es extraordinariamente flexible. No podemos decir que los pilares próximos al núcleo no estén activados por esta losa ante las acciones horizontales, pues la relación ancho-alto del edificio es muy pequeña, pero en su diseño el pensamiento parece cifrado en reducir al núcleo central el papel de resistir estas acciones.

- Un paso más en la colaboración de los pilares de borde con el núcleo lo da Golberg en el edificio Marina City, en Chicago (Fig. 18), de $180 \mathrm{~m}$ de altura y 64 plantas. El forjado está constituido por una serie de vigas radiales sobre las que se puentea una losa ligera de 12 centímetros.

El empotramiento en el núcleo de estas vigas se realiza por intermedio de unos pilares situados en la proximidad del núcleo y que con éste proporcionan el empotramiento requerido en las vigas.

- En el «Australia square», en Sydney, de 184 m de altura (Fig. 19), se ha utilizado casi exactamente el mismo esquema resistente.

Para hacer más eficaz la colaboración entre núcleo central y pilares de contorno es necesario aumentar la rigidez de las vigas del forjado. $Y$ esto se pue- de conseguir concentrando toda la rigidez de las plantas en unas vigas de gran canto - de la altura de un piso- colocadas en la parte superior del edificio o distribuidas a lo largo de él utilizando, para ello, las plantas intermedias de servicios.

Dos ejemplos notables de este dispositivo resistente, uno en acero y otro en hormigón, son buenos ejemplos de lo dicho. El United States Steel Building de Pittsburg, de $256 \mathrm{~m}$ de altura y 64 plantas, presenta dos aportaciones importantes (Fig. 20). El núcleo central formado por una triangulación metálica se dispone en el triángulo central que rodea a los ascensores. La segunda es la disposición en la parte superior del edificio de las vigas de gran canto.

El segundo edificio es de hormigón, el Place Victoria office Building, en Montreal, de $190 \mathrm{~m}$ de altura y 51 plantas, construido antes que el anterior, en 1964, y en el que colaboró P. L. Nervi (Fig. 21). Este edificio tiene un núcleo central en forma de cruz, según las diagonales del cuadrado de la planta, y se une a los cuatro grandes pilares de esquina por medio de grandes vigas, con canto igual a una planta,

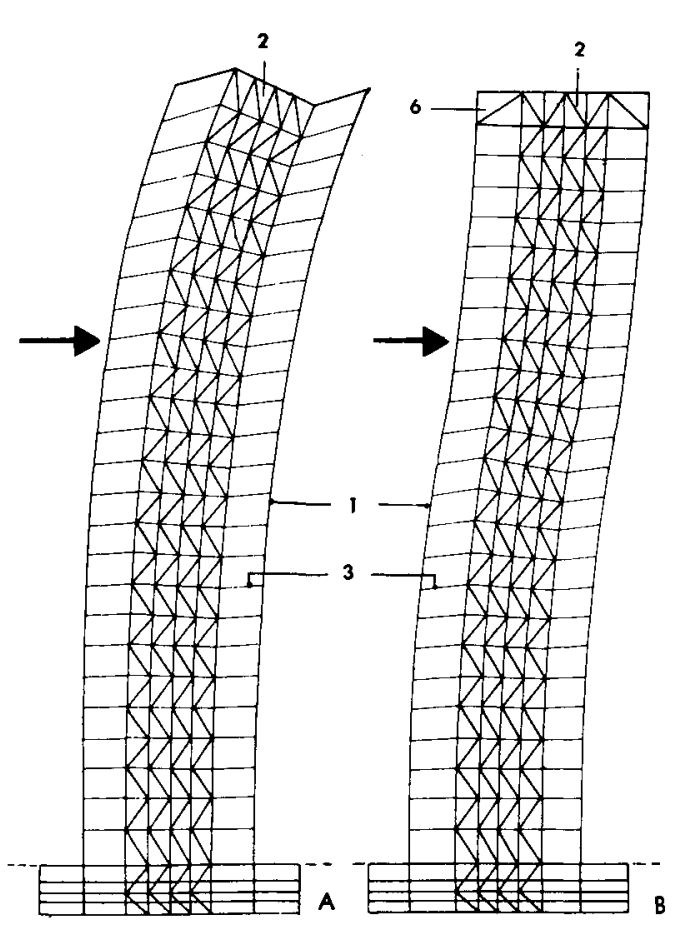

FIGURA 20

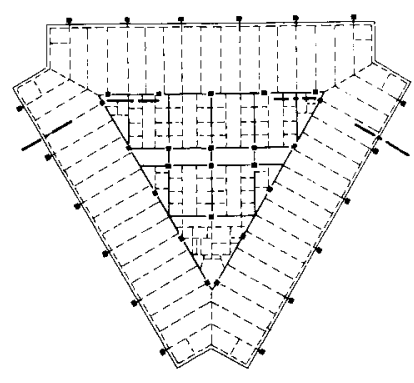

Planta

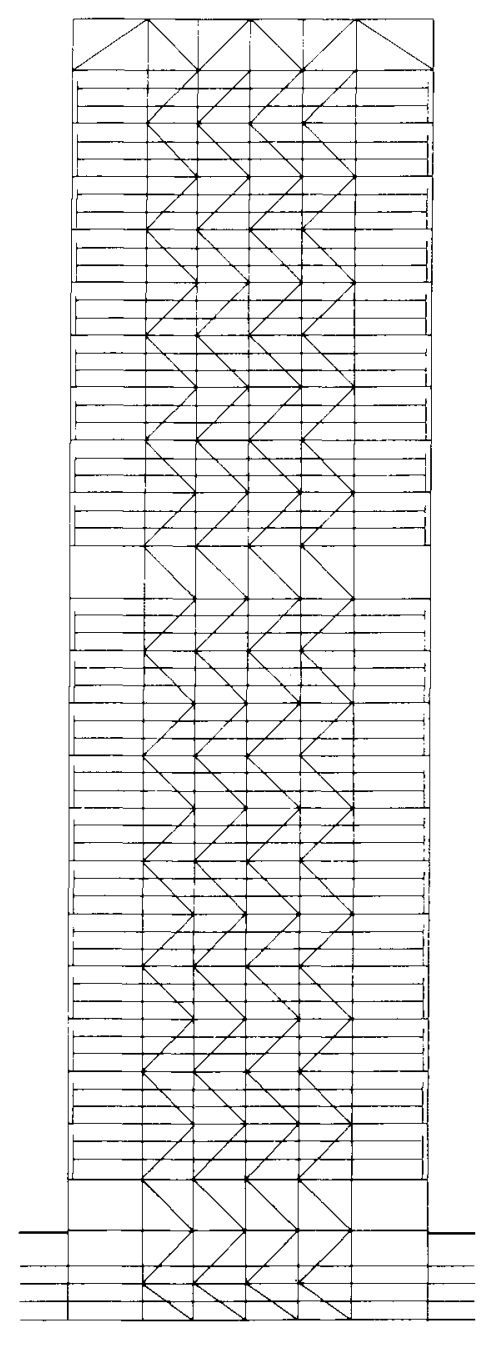

Sección 
situadas en los cuatro niveles donde se sitúan las plantas de instalaciones.

\subsection{Tubos}

En 1965 se construye el edificio de apartamentos DeWitt-Chestnut, en Chicago, de 43 pisos y 120 m
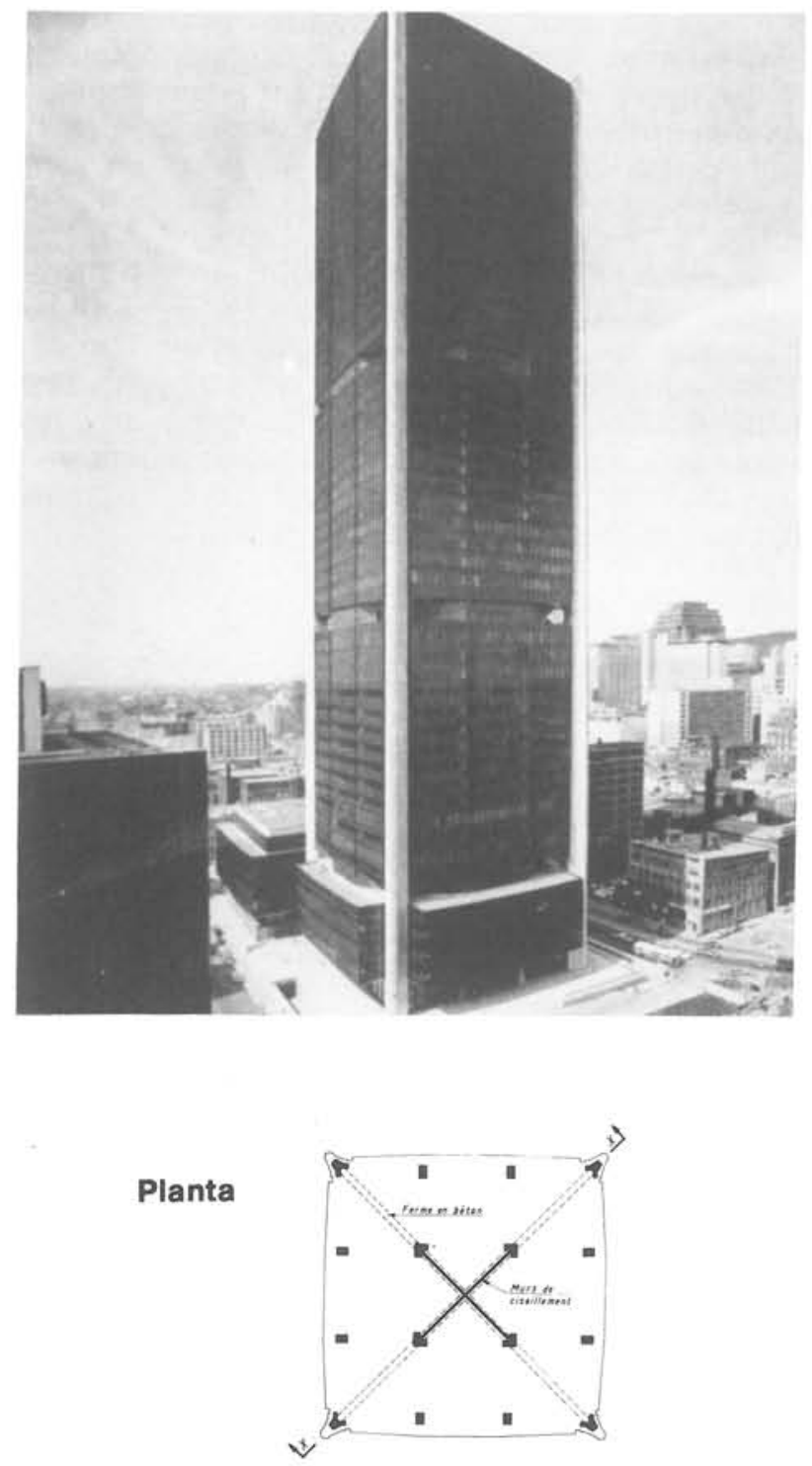

Sección vertical

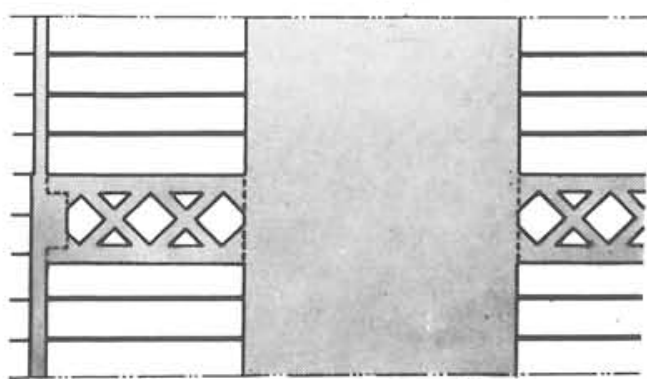

de altura, en hormigón armado. Es el primer edificio que utiliza la solución «tubo» para hacer frente a las cargas horizontales (Fig. 22). Esta solución se ha generalizado después para los edificios de muy gran altura.

La estructura tubo podría definirse como una gran viga cajón perforada por las ventanas y que constituye la fachada del edificio. Podría también definirse como una estructura aporticada espacial dispuesta en las fachadas del edificio, en la que la separación entre pilares es muy pequeña, del orden de 1,2 a 3 m como máximo, y las vigas horizontales, dispuestas en cada planta del edificio, con un canto variable entre $0,6 \mathrm{~m}$ y $1,2 \mathrm{~m}$, con anchuras variables entre $0,25 \mathrm{~m}$ y $0,9 \mathrm{~m}$ (dimensiones según $\mathrm{F}$. Khan).

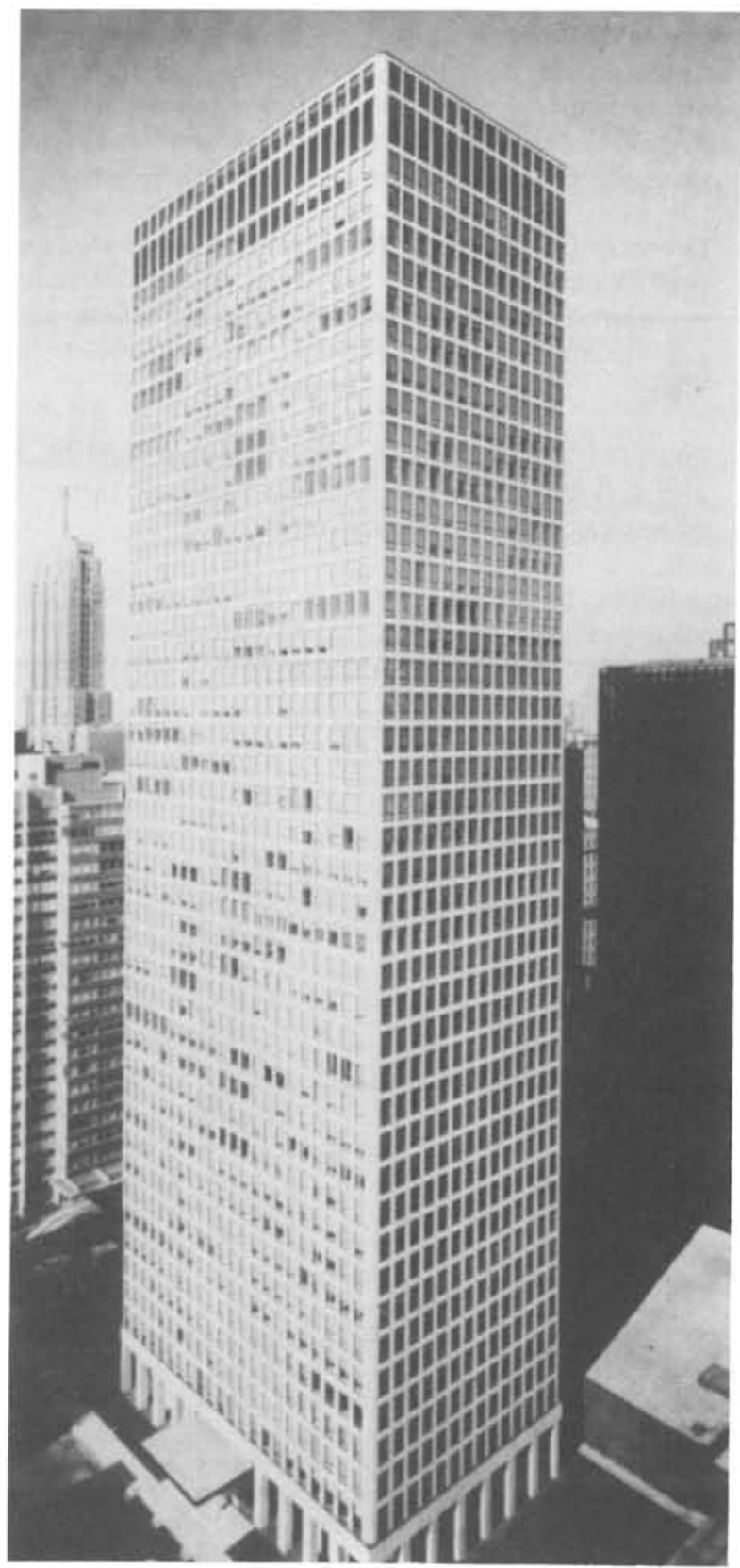

FIGURA 22 
Cuando hablábamos en 4.1. de la estructura aporticada veíamos que, en su deformación total, intervenía con carácter predominante la deformación por cortante y que esta deformación [ver foŕmula (1)] dependía en razón directa de la separación entre pilares I y en razón inversa de la inercia de vigas y pilares. La intención subyacente en la estructura "tubo" es minimizar la deformación por cortante, para lo cual nada mejor que reducir l y dimensionar vigas y pilares adecuadamente.

De esta manera se consigue que la deformación principal sea la de flexión y el estado tensional que solicita al tubo se separa poco de su vocación, que es la lineal como corresponde a un estado de deformación plano de las secciones.

Resulta evidente que si se adoptan vigas horizontales y pilares de mucha inercia se puede llegar a una perfecta linealidad del estado tensional, pero esto puede ser caro. El dimensionamiento de la célula elemental del tubo, la formada por un pilar y una viga cortados en el punto medio de su altura y luz respectivas, debe ser cuidadosa con el fin de equilibrar rendimiento resistente y coste.

No hay que olvidar tampoco que la reducción de la deformación por cortante en la deformación total del pórtico depende de la relación ancho-altura. Para una determinada anchura del edificio y para unas determinadas condiciones de dimensionamiento de la célula elemental del tubo, la participación del mecanismo de flexión en la deformación total crece con el cuadrado de la altura, mientras que la deformación por cortante es lineal con ella.

Este fenómeno es similar, aunque más intenso, al que se produce en las vigas de alma llena. Cuando la relación canto-luz es muy grande no puede despreciarse la deformación por cortante; la deformación de la sección no es plana y el estado tensional tampoco. Por el contrario, cuando esta relación es pequeña, la deformación por cortante es despreciable, las secciones se conservan planas y el estado tensional también. Este mismo planteamiento es válido para las vigas cajón de alma llena y la distribución del estado tensional en las cabezas es uniforme sólo en el caso de relaciones pequeñas ancho-luz. En caso contrario la deformación por cortante - shear lag- determina una distribución tensional no uniforme en las cabezas, con concentración cerca de las almas y reducción en las zonas alejadas de ellas.

En la figura 23 comparamos el estado tensional ideal, si el tubo no tuviera deformación por cortante $y$ el real.

Para el predimensionamiento $F$. Khan ha desarrollado ábacos en función de parámetros significativos:

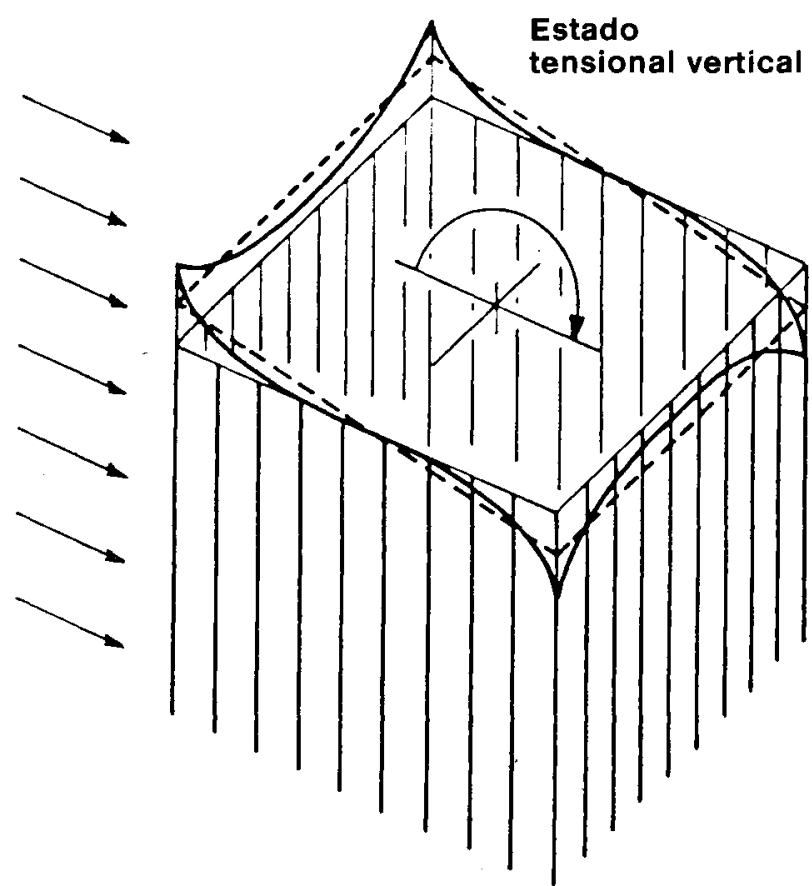

-..- Sin tener en cuenta la deformación por esfuerzo cortante.

- Estado tensional real.

FIGURA 23

Relación de rigidez $=\frac{K_{c}}{K_{b}}=$

$$
=\frac{\text { rigidez de columnas }}{\text { rigidez de vigas }}=\frac{I_{c} / h}{I_{v} / \ell}
$$

Factor de rigidez $=\frac{S_{\mathrm{b}}}{S_{\mathrm{C}}}=$

$=\frac{\text { rigidez equivalente a cortante de las vigas }}{\text { rigidez axil de las columnas }}=$

$$
=\frac{\frac{12 \mathrm{E} \cdot l_{v}}{\ell^{3}}}{\frac{E \cdot A}{h}}
$$

Factor de forma $=\frac{\text { canto del tubo }}{\text { ancho del tubo }}$

y todo ello en función de la altura del edificio.

El cálculo exacto hay que realizarlo con un emparrillado plano, similar al representado en la figura 24 en el cual la conexión entre cabezas y almas se materializa con una vinculación a cortante.

La utilización del tubo, como estructura resistente a los efectos de las cargas horizontales, libera al interior del edificio de las exigencias del viento y son exclusivamente las cargas gravitatorias las que condicionan su diseño. Sin embargo conviene ordenar la estructura horizontal de los pisos para que la máxima carga posible sea recogida por las paredes del tubo. 


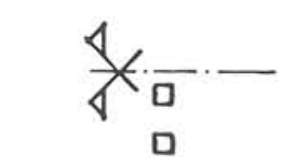

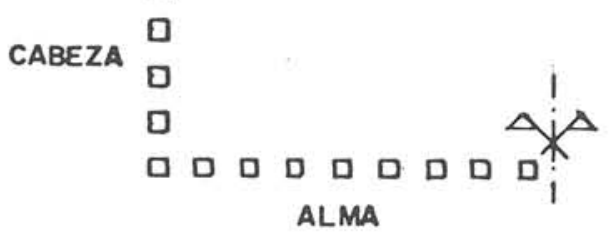

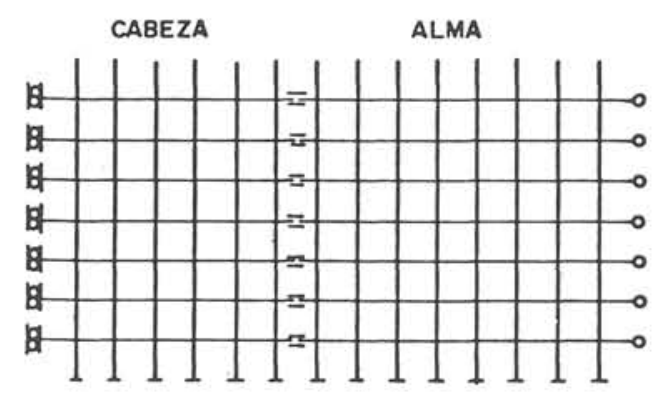

FIGURA 24
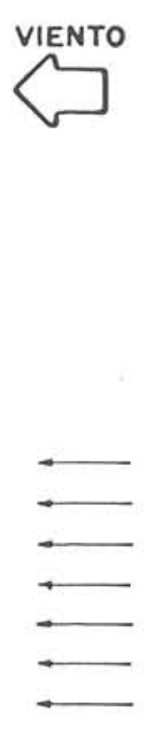

Esta tipología estructural se ha realizado tanto en hormigón como en acero $y$, en sus versiones mezcladas, se realizarán el tubo de hormigón y las plantas y pilares interiores metálicos. En la figura 25 representamos la máxima realización de una estructura en "tubo» metálico, el World Trade Center, en Nueva York, con 110 plantas, 412 m de altura y $63,5 \times 63,5 \mathrm{~m}$ de dimensión en planta.

Si la voluntad expresada en la estructura tubo es reducir al máximo la deformación por esfuerzo cortante del pórtico espacial, esto se consigue mucho más eficazmente que cerrando la malla de vigas y columnas, triangulándolas. Transformar una viga Vierendel en otra triangulada. Este procedimiento se ha realizado en una serie de edificios tanto metálicos como de hormigón y aquí traemos el más representativo y grande, una de las obras maestras de Fazlur Khan, el John Hancock Center de Chicago (Fig. 26). Este edificio es tronco-piramidal, tiene 100 plantas, $336 \mathrm{~m}$ de altura y una base inferior de $80,2 \times 50,3 \mathrm{~m}, \mathrm{y}$ una base superior de $48,8 \times 30,5 \mathrm{~m}$.

La triangulación confiere al tubo una rigidez tal que todos los pilares verticales y los diagonales actúan solidariamente tanto para las cargas verticales como para el viento. En la figura 27 se puede observar la distribución de tensiones en las caras del edificio, en los dos casos de cargas.

Por último y siguiendo con los edificios que utilizan la «piel» para contrarrestar el efecto de las cargas horizontales, vamos a considerar un edificio de hormigón especialmente interesante. Se trata del Ayuntamiento, en Toronto (Fig. 28), de treinta plantas y $99 \mathrm{~m}$ de altura. Estos edificios utilizan las fachadas posteriores que, por su forma en planta, se comporta como una estructura laminar rigidizada por las losas de pisos.

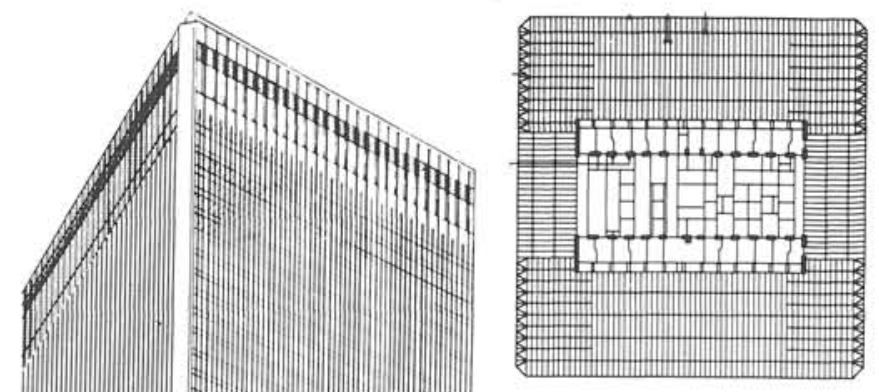

Estructura del forjado

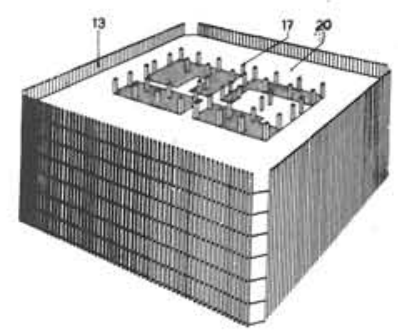

Estructura tubular:

arriostramiento de las paredes exteriores portantes por las losas de forjados.

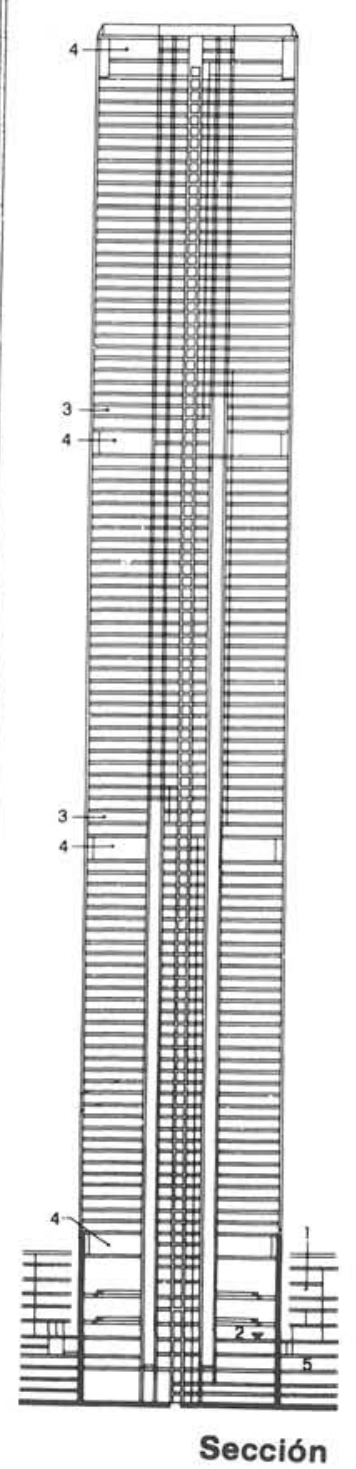




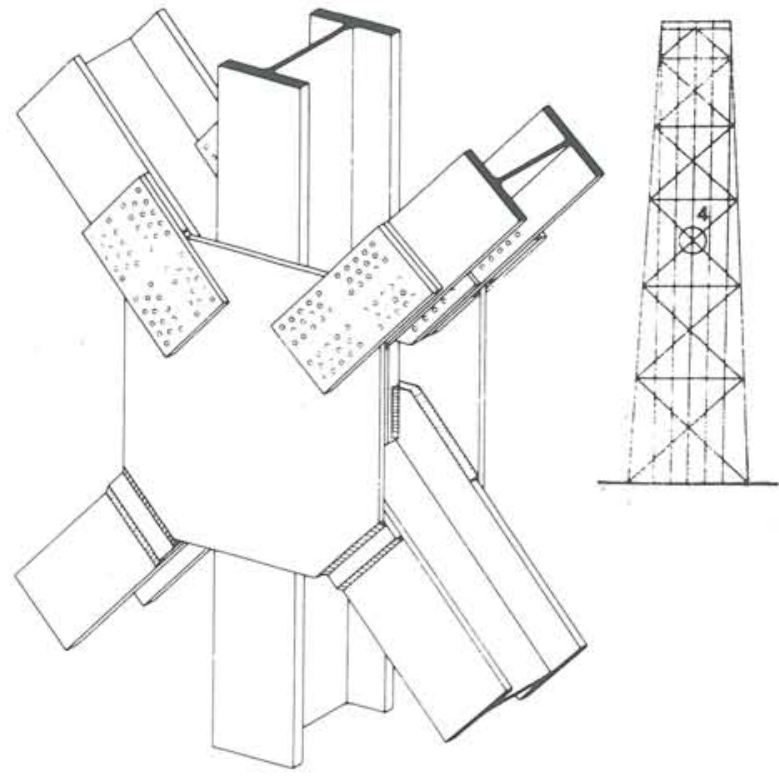

Representación simplificada del nudo principal del entramado vertical.

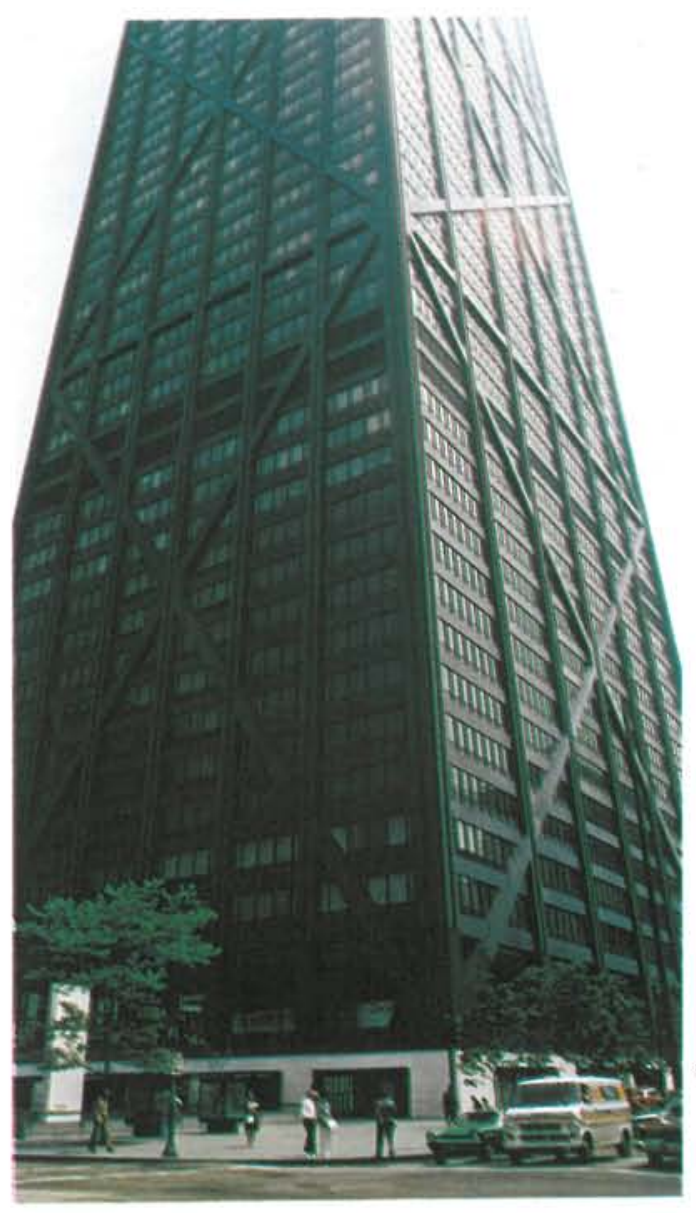

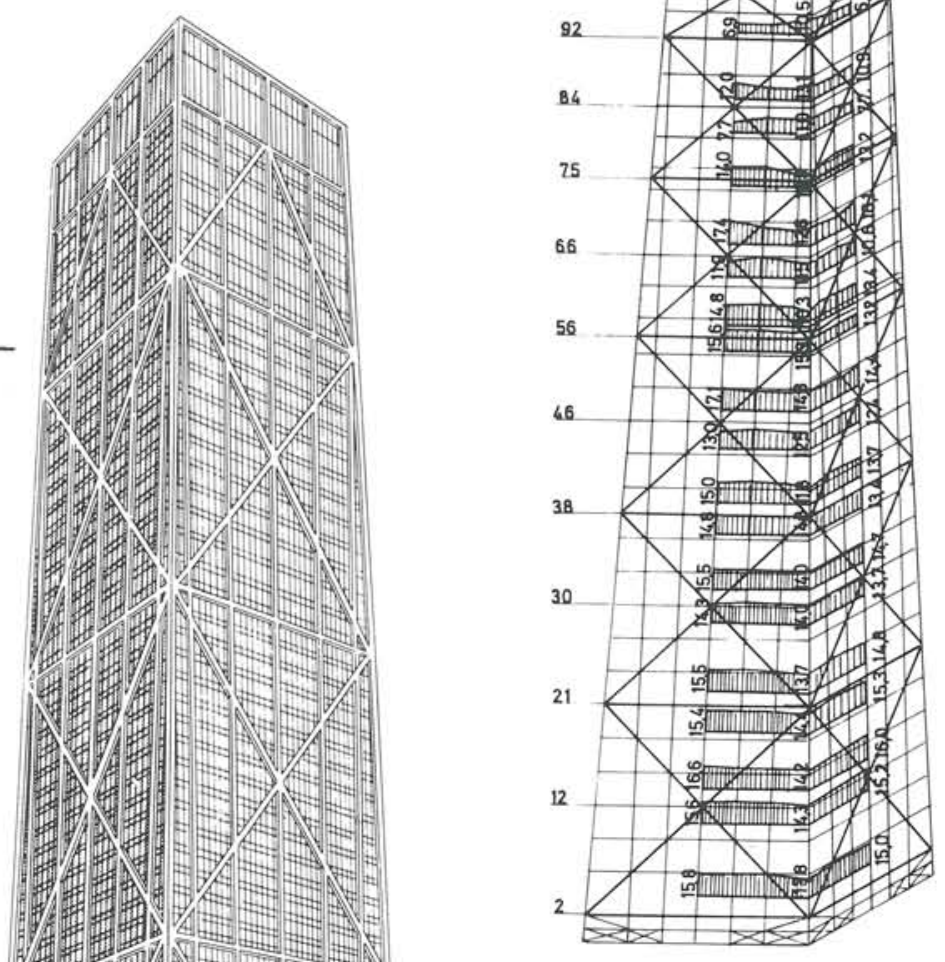

II

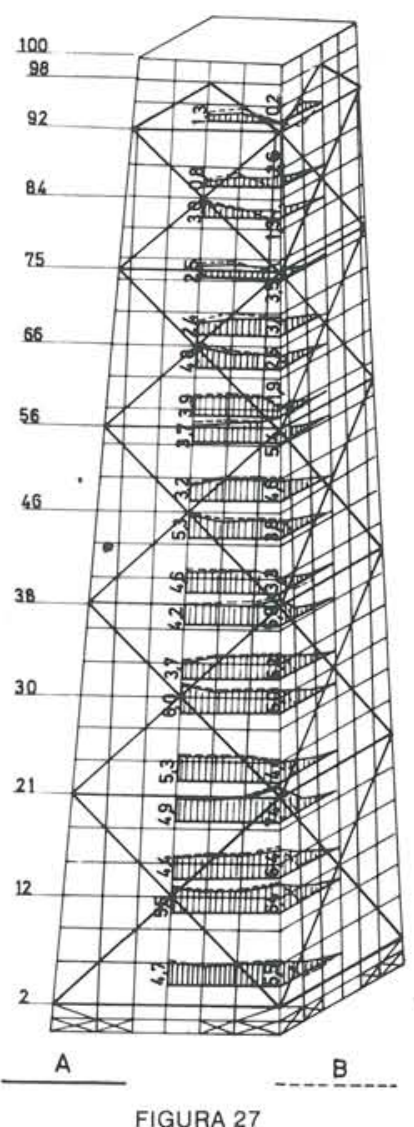



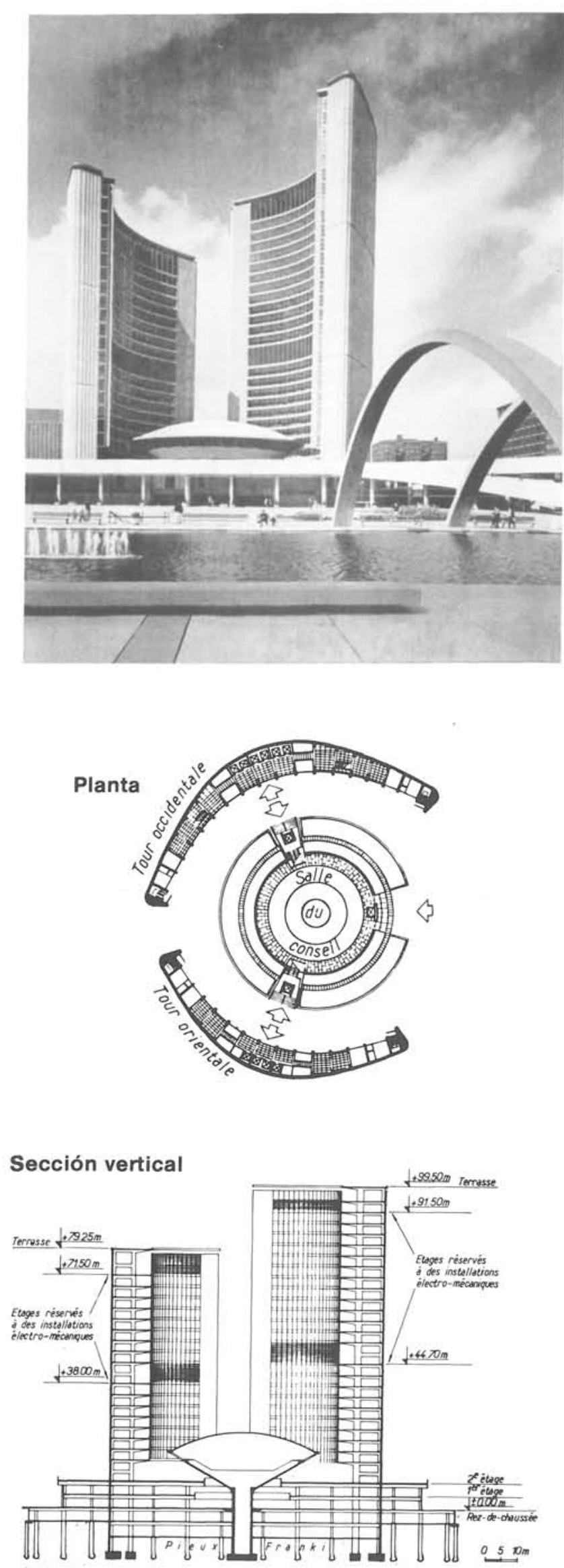

FIGURA 28

\subsection{Tubo en tubo}

Si unimos la idea de concentrar la rigidez al viento en la fachada propia del «tubo», y la idea del núcleo central necesaria generalmente para la instalación de ascensores y servicios, y conectamos ambas estructuras por el forjado, tendremos el tubo en tubo.

Son tres los mecanismos resistentes que se ponen en juego en la resistencia al viento:

1. ${ }^{\circ}$ La rigidez a flexión y cortante del núcleo central.

2. ${ }^{\circ}$ La rigidez a flexión y cortante del tubo exterior.

3. ${ }^{\circ}$ La conexión entre ambos a través de la rigidez a flexión de las losas de pisos.

La realización más espectacular de este tipo estructural la constituye el "One Shell Plaza», en Houston, de Fazlur Khan (Fig. 29). Tiene 52 plantas, $218 \mathrm{~m}$ de altura y fue construido en 1967-1968.

De la misma manera que Goldberg en las torres de "Marina City», en Chicago, Khan establece unos pilares separados del núcleo que permiten un empotramiento más fácil de la losa en el núcleo, a la vez que reduce la luz libre del forjado. La concentración de cargas en los pilares de fachada enfrentados con las esquinas del núcleo, que veíamos en 4.4., se manifiesta en este edificio con un cambio de dimensión, lo cual determina un movimiento superficial de la fachada.

\subsection{Tubos múltiples}

El Sears Building de Chicago, de 110 plantas y 443 metros de altura, es el mayor edificio realizado en el mundo (Fig. 30). En este edificio F. Khan utiliza el concepto de la estructura tubo, pero extendida no sólo a las fachadas sino también a su interior, de modo que se obtiene una viga cajón de cuatro almas en cada dirección, en lugar de sólo dos.

La eficacia resistente de esta distribución es mejor que el tubo normal, ya que no sólo se cuenta con cuatro almas sino que las cabezas del edificio, frontales al viento, experimentan deformaciones por cortante más pequeñas, por ser activadas por cuatro almas en lugar de por dos (Fig. 31).

Esta organización de la estructura resistente permite el juego de volúmenes que ofrece el edificio al exterior, pues cada uno de los nueve cuadrados en que se subdivide puede interrumpirse a cualquier altura. 


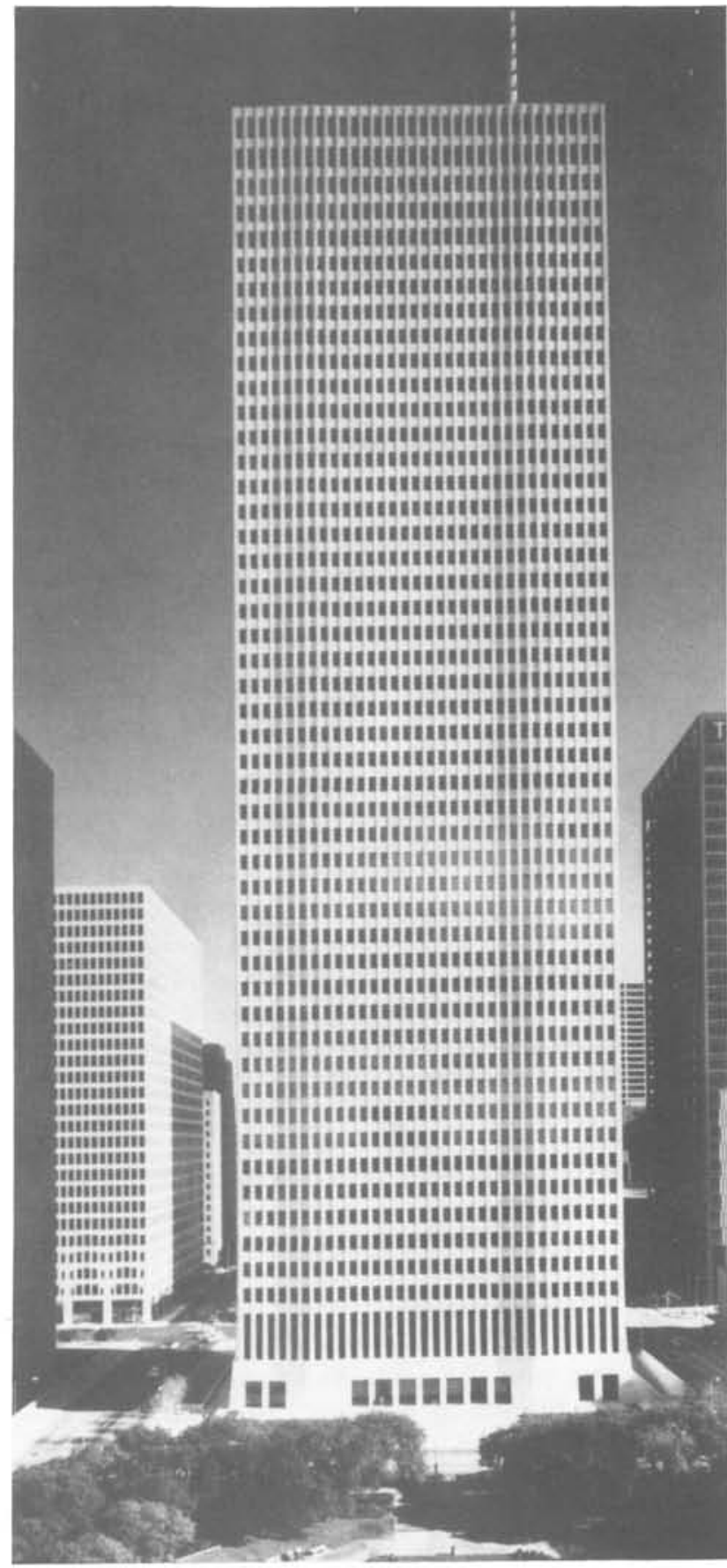

Planta de estructura

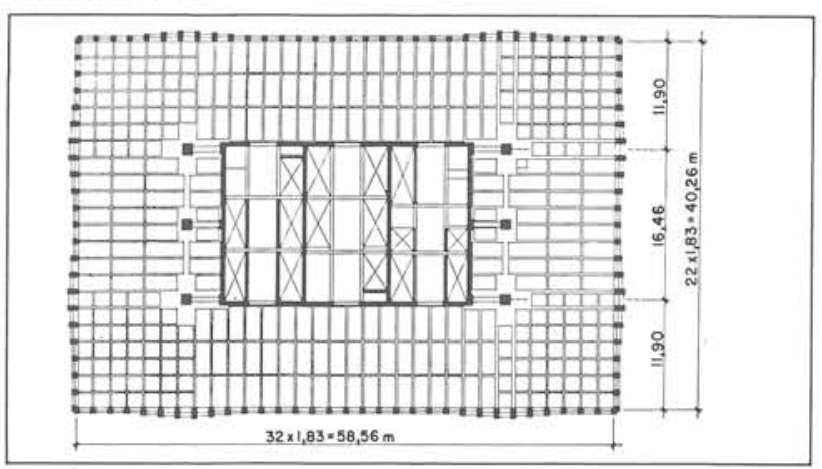

FIGURA 29

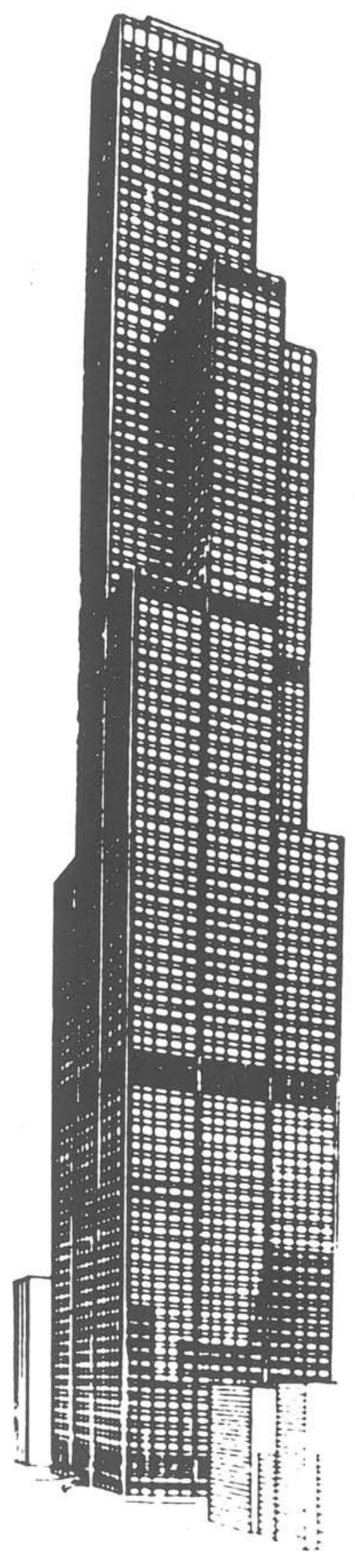

FIGURA 30 


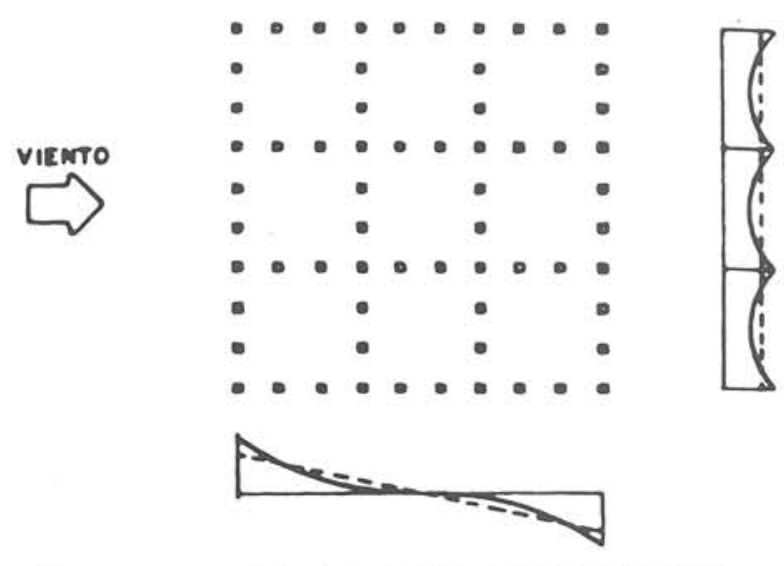

... Sin tener en cuenta la deformación por esfuerzo cortante. - Estado tensional real.

FIGURA 31
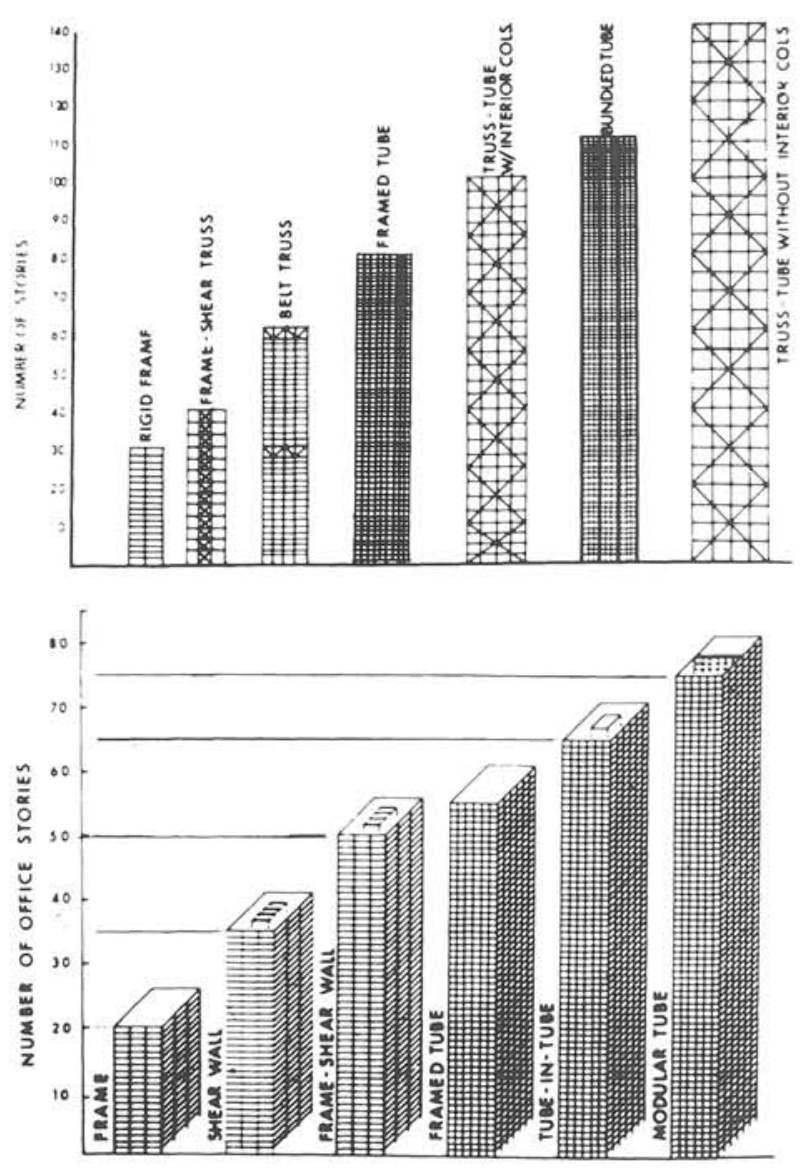

FIGURA 32

\subsection{Tipologías estructurales a utilizar en función de la altura}

Hemos ido analizando diversos tipos estructurales para edificios de gran altura. Los límites de validez de cada solución son bastante imprecisos dependiendo de multitud de factores. En la figura 32 representamos la ordenación planteada por Khan en función del número de plantas.

Se podría hacer un comentario a esta clasificación desde la pura especulación y, por tanto, con todas las limitaciones que se quiera.

Mirando la clasificación por la parte inferior parece excesivo acudir a la estructura pórtico hasta alturas de 30 plantas, para solución en edificio metálico, o 20 plantas para edificio de hormigón, cuando para estas alturas es fácil contar con un núcleo central resistente a viento o disponer pantallas que lo abaratarian bastante.

En cuanto a la clasificación en la parte más alta se pueden plantear dudas respecto a la utilización, en general, del tubo múltiple. Esta solución plantea unas exigencias dentro del edificio que parecen excesivas, además de ser una solución que en principio no parece barata. Generalmente la disposición de almas intermedias en una viga cajón resulta cara. Parece mucho más interesante cubrir la zona adjudicada al tubo múltiple con la celosía triangulada de piel sin disponer columnas interiores. En el caso de que la planta sea muy grande y el coste de los forjados muy elevado, podrían utilizarse las plantas intermedias destinadas a instalaciones para disponer plataformas de gran rigidez que puentean el edificio de lado a lado, y el resto de las plantas soportarlas con pilares intermedios que se refieren a la fachada a través de las plantas rígidas.

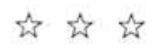

